\title{
A Novel Scenario-Based Bi-objective Optimization Model for Sustainable Food Supply Chain During the COVID-19: a Case Study
}

\author{
Maede Azani $^{1} \cdot$ Mohammad Shaerpour $^{1} \cdot$ Mohammad Amin Yazdani $^{1,2} \cdot$ Amir Aghsami $^{1,3}$ (D) $\cdot$ Fariborz Jolai $^{1}$ (i)
}

Received: 9 June 2021 / Revised: 28 September 2021 / Accepted: 3 October 2021 / Published online: 10 November 2021

(c) The Author(s), under exclusive licence to Springer Nature Singapore Pte Ltd. 2021

\begin{abstract}
Since food is one of the essential human needs, studies on this topic have always been a global concern. With the advent of COVID-19 and the emergence of many problems in all aspects of the food supply chain (such as production, transportation, distribution), this issue has become doubly important. This paper discusses an MINLP optimization model for handling the impact of the COVID-19 pandemic based on the food supply network through Food Hubs (FHs). In this research, the concept of FH has been used for a more effective and faster connection of consumers to production sites. Due to prevention of the spread of coronavirus and the quarantine conditions, the areas have been divided into two parts (high-risk and low-risk) and two scenarios have been defined for this supply chain. The purpose of this paper is to reduce costs and environmental impacts as much as possible. The proposed model is solved by GAMS software for small- and middle-size test problems, and it is solved with genetic optimization algorithm as a meta-heuristic approach for large-size problems. Also, to solve the developed linear multi-objective model, augmented $\varepsilon$-constraint approach is applied, and a real case study from Iran is examined to illustrate the validation of the proposed model. Numerical and computational results are provided to prove the efficiency and feasibility of the presented model. Finally, sensitivity analysis is presented to evaluate the effect of changing some parameters on variables and objective functions.
\end{abstract}

Keywords Food supply chain · COVID-19 · Genetic algorithm · Sustainability

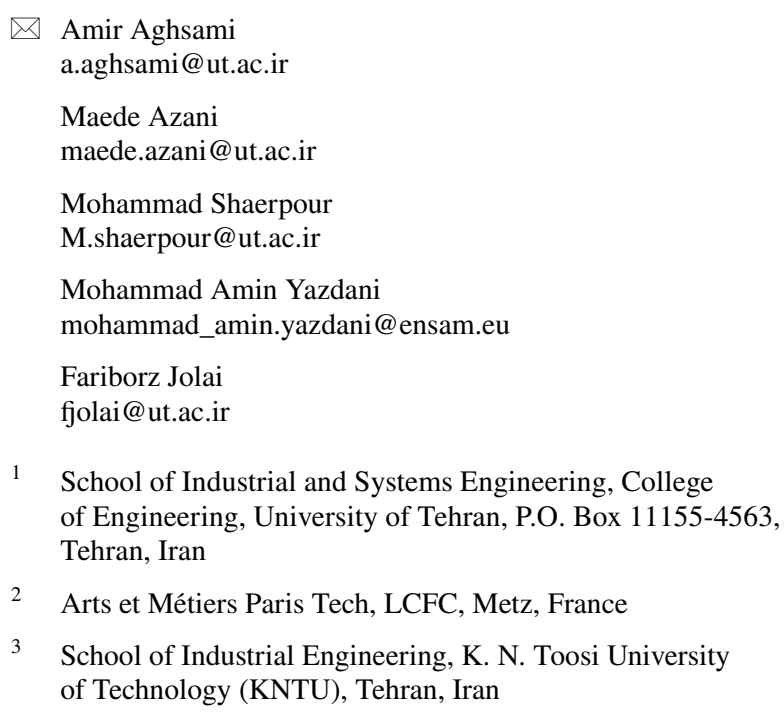

3 School of Industrial Engineering, K. N. Toosi University of Technology (KNTU), Tehran, Iran

\section{Introduction and Literature Review}

Food not only plays a very important role in human health, but also it is one of the most important economic and environmental elements in the world. So, disruption of the food supply chain can cause many problems.

Supply chain disruptions can occur owing to human-made disasters and natural calamities. Globally, several instances occurred in the past, such as the Gujarat earthquake (2001), the tsunami in Japan (2011), the Indian Ocean earthquake, and tsunami (2004) (Singh et al. 2021), and now, COVID-19.

For a closer look and better understanding, the relevant explanations are given in separate sections.

\section{Coronavirus Impact}

Since December 2019, the coronavirus disease 2019 (COVID-19) has entered the world into a new era. It began in Wuhan city. Coronaviruses circulate among animals, and in some cases, may infect humans (Rizou et al. 2020). This 
virus is easily transmitted from person to person, and it is very lethal.

With the spread of COVID-19, many governments made quarantine mandatory for months. As you know, the food system has a lot of complexity, and coronavirus has made it harder. As a result, this pandemic causes significant job losses, which will drive down demand and lead to a severe, comprehensive economic crisis (De Vito and Gómez 2020). This lockdown has also disrupted both domestic and foreign supply chains.

During the COVID-19 era, food safety has become one of the most important components. The pandemic has also changed consumer behavior in choosing food. Consumers seek to protect themselves and improve their immune systems (Perdana, Chaerani et al. 2020). Nowadays, we have to prevent the spread of this virus in any way we can. On the other hand, food is one of the basic human needs. Moreover, it is of the highest importance for the food sector to ensure that the food reaching consumers' plate is safe and does not risk their health at any step of the process (e.g., even at the moment of delivery) (Rizou et al. 2020). So, we need to define a sustainable and efficient food system. This is where the concept of FH (food hub) comes in.

The food hub is an organization (centralized facility, rural development, and so on) that manages the aggregation, distribution, and marketing of source-identified food products from local producers to strengthen their ability to satisfy wholesale, retail, and institutional demand. One of the primary goals of food hubs is to give small- and medium-sized farmers access to larger or additional markets, lower entry barriers, and create new infrastructure.

Mahajan and Tomar (2021) showed that long-distance food supply chains had been hit the hardest during the current pandemic with welfare consequences for urban consumers and farmers. As long as we move from farm to fork, more safety measures are needed since more people (and subsequently more potential sources of infection) are involved in the process. The need for developing respective bioanalytical protocols for food and environmental safety applications to adapt in the post-lockdown period is also highlighted (Rizou et al. 2020).

Multi-way policies may influence supply chains to avoid the disease's spread, either in supply, demand, or logistics. Grida et al. (2020) showed that demand is the most affected aspect of the supply chain by COVID-19 prevention policies. Hobbs (2020) discussed the effects of demand-side shocks on food supply chains, including consumer panic buying behaviors concerning key items and the sudden change in consumption patterns from the foodservice sector to meals prepared and consumed at home.

COVID-19 resulted in workers' movement restrictions, changes in consumers' demand, closure of food production facilities, restricted food trade policies, and financial pressures in the food supply chain. Therefore, governments should facilitate the movement of workers and agri-food products. Moreover, small farmers or vulnerable people should be supported financially. Facilities should change the working conditions and maintain employees' health and safety by altering safety measures (Aday and Aday 2020). Besides, in the epidemic of coronavirus, more measures are needed for food safety. Researchers and professionals in the food sector have many challenges ahead. There are some challenges that Rizou et al. (2020) had mentioned: ensuring food safety, detecting the virus in environments where food is produced, processed, and delivered, sanitizing surfaces, and working environments adequately, and others. Perdana et al. (2020) offered the concept of RFHs to connect the production of rural and urban consumers. This article aims to determine the location and capacity of RFHs, increase food supply, and minimize the cost of supplies. They provided a Multi-Objective Many-to-Many Location Routing Problem model. Due to the coronavirus epidemic, they considered demand and production uncertain and used robust optimization for uncertainty.

\section{Sustainability}

Food supply will need to increase by around $70 \%$ from its current levels to meet the world population growth of 9.6 billion by 2050 . Food waste is the biggest challenge in global food security, wherein approximately $20-30 \%$ of food waste occurs in the post-harvest stage of the food supply chain (FSC) in developing countries (Krishnan et al. 2020).

Sustainable supply chain management has been a topic of high interest to scholars and practitioners over the last 30 years. Accordingly, many review papers have been published on this topic with various areas of focus. Increasing food supply chain sustainability means dealing with many conflicting aspects involving producers, several distribution company departments, and consumers (Segura et al. 2020). Supply chain sustainability refers to the transparent integration and achievement of organizations' social, environmental, and economic goals through the effective coordination of internal organizational processes. In other words, material flow management, information, and coordination throughout the supply chain, considering three economic, social, and environmental dimensions, is called a sustainable supply chain. Only by making the FSC more sustainable and ensuring a waste reduction, it is possible to address the increasing food demand.

Ogier et al. (2013) developed efficient solving methods for an original service network design problem imbued with sustainable issues. They designed the network for short and local supply chains and fresh food products. They proposed a Mixed Integer Programming formulation for this problem. 
With consumer consciousness growing in the area of sustainable food supply, food distribution needs to embrace and adapt to improve its environmental performance while remaining economically competitive. Saetta and Caldarelli (2020) examined how to increase the stability of the food chain through a case study. They had conducted surveys of various companies in the agricultural, transportation, and food sectors and showed that identifying logistical advances and technological innovations had a significant impact on supply chain sustainability.

We can also take advantage of the implementation of digital technologies. Junge and Straube (2020) presented findings concerning the prospects of implementing digital transformation technologies (DTT) for more sustainable processes in manufacturing companies' logistics and supply chain management. DTT can enable improvements regarding energy efficiency, reducing transport and distribution distances, and optimizing logistics resources. Junge and Straube (2020) developed DTT in logistics and supply chain management, which positively impacts the environment and social sustainability dimension.

In addition to the economic aspects, the environmental aspects are very important. A great portion of resources (natural, environmental, etc.) are related to the production and distribution of food, and every single part of this system has its particular effect on resources. A tomato grown locally in a greenhouse in the Netherlands, for example, will have a different environmental footprint than a tomato grown in Italy or Spain (Rohmer et al. 2019).

The environmental dimension of sustainability mainly focuses on issues related to environmental management. Such issues include depleting natural resources, releasing toxic gases into the environment, energy consumption, water consumption, and waste generation. The pressure of sustainable development is not only exerted by the government but also by the customer. Awareness among the society and strict government regulations force the industries to reduce environmental impact from their supply chain (Dhull and Narwal 2018). These FSCs are also responsible for $31 \%$ of greenhouse gas emissions and more than $50 \%$ of eutrophication (Liu 2018). Consumer health and the reduction of GHG (greenhouse gas) emissions are investigated as the social and environmental objectives, respectively, besides the supply chain members' profit. GHG emissions increase as the government penalty for endangering consumer health rises. Alliances between supply chain members are economically beneficial when product demand depends more strictly on reducing GHG emissions (Nematollahi and Tajbakhsh 2020). For more reading, refer to Mohtashami et al. (2020), Ferrari et al. (2019), Eustachio Colombo et al. (2019), Fakhrzad and Goodarzian (2019), and Ganguly et al. (2019).

\section{Agri-food Supply Chain}

The importance of food quality, safety, and weather-related variability differentiates the agri-food supply chain (ASC) from other supply chains. Other relevant characteristics of agri-foods include their limited shelf life, demand, and price variability, making the underlying supply chain more complex and harder to manage than other supply chains (Ahumada and Villalobos 2009). The use of integrated planning models in the ASC is still very limited. While Ahumada and Villalobos (2009) believed that these models would be useful in modeling all the agri-food products, They concluded that the focus of agricultural planning had been mostly on non-perishable products. Perhaps, the lack of research on perishable products was due to the perceived less importance of these crops over the traditional or program crops such as wheat, corn, and cotton. Among the agricultural commodities, the food item had been least explored in supply chain management. Ganesh Kumar et al. (2017) addressed this limitation through a structured agri-food supply chain management review. Also, in past, present, and prospective themes of sustainable agricultural supply chains, Nematollahi and Tajbakhsh (2020) presented an extensive review of 247 quantitative studies on sustainable agricultural supply chains. They classified the collected materials based on different structural dimensions and related analytic categories obtained from deductive and inductive categorization techniques.

\section{Motivation, Research Gaps, and Contributions}

According to studies, the supply chain plays a crucial role in providing the food needed by people in the community. During quarantine, to prevent the spread of the coronavirus, the importance of food supply increases. Furthermore, the economic dimension has been studied as the most critical factor in the articles, and less attention has been paid to the environmental and social dimensions. The supply chain must be efficient and, at the same time, have few destructive environmental effects.

Therefore, in this study, we design a food supply chain compatible with the coronavirus epidemic. In this method, locations are divided into regions, and for each, FH is considered. Then, we define two scenarios for limitations of trading between other areas and high-risk areas. The proposed model minimizes both environmental as well as cost aspects while respecting the preventing the spread of coronavirus, and it is solved by GAMS software for small- and middle-size test problems and genetic optimization algorithm as a meta-heuristic approach for large-size problems, and to solve the developed linear multi-objective model, the augmented $\varepsilon$-constraint approach is applied. Also, a case study from Iran is presented. 
This paper contributes to the literature in various ways. First, it controls the communication between areas covered by the supply chain. This will reduce the spread of the virus and involve fewer people. It also manages the communication between areas to prevent food shortages and control consumers' panicked behavior to provide food during quarantine.

Second, using the food hub concept, this paper increases supply chain sustainability, demand fulfillment, food affordability, accessibility, safety, and security to ensure food availability of the local food system at all times, especially in the coronavirus epidemic.

Third, by designing a sustainable food supply chain that includes three levels of production, distribution, and consumption, in addition to reducing costs as an important economic indicator, it tries to reduce the destructive environmental effects caused by the production and transportation of products.

The remainder of this paper is organized as follows: the nomenclature is presented in the "Nomenclature" section; the research methodology and mathematical formulation are presented in the "Research Methodology" section; the "Numerical Examples" section presents numerical examples. The "Case Study" section presents the case study; discussion and conclusion are presented in the sections "Discussion and Managerial Insights" and "Conclusion and Future Study."

\section{Nomenclature}

The following notations are as follows:

Sets and index

$S \quad$ set of locations indexed by $i . j \epsilon S$

$B$ set of FHs $(B \subset S)$

A sets of consumers indexed by $l \epsilon A$

$P \quad$ set of products indexed by $p \epsilon P$

$R \quad$ set of high-risk area indexed by $r(\mathrm{r} \epsilon \mathrm{R})$

$C$ set of low-risk area indexed by $c(\mathrm{c} \epsilon \mathrm{C})$

Parameters

$f_{p i} \quad$ the production capacity of product $\mathrm{p}$ on production location $i$

$d_{p i} \quad$ demand for product $\mathrm{p}$ at location $i$

$s_{p j} \quad$ the capacity of $\mathrm{FHj}$ for product $\mathrm{p}$

dist $_{i j}$ distance between production center $i$ and $\mathrm{FH} \mathrm{j}$

int $_{j l} \quad$ distance between $\mathrm{FH} j$ and consumer 1 $c p_{i p} \quad$ cost of producing of product $\mathrm{p}$ in production location i

$e p_{i p} \quad$ environmental impact of producing of product $p$ at production location $i \in S$

et unit environmental impact of transportation

$c t_{u} \quad$ unit transportation cost from production locations to FHs

$c t_{y} \quad$ unit transportation cost from FHs to consumers

Variables

$y_{j l p} \quad$ quantity of product $\mathrm{p}$ transported from $\mathrm{FH} \mathrm{j}$ to consumer 1

$u_{i j p} \quad$ quantity of product $\mathrm{p}$ produced in production location $i$ and transported to $\mathrm{FH} j$

$x_{i p} \quad$ quantity of product $\mathrm{p}$ produced at production center $i$

EP total environmental impact related to production activities (including agricultural and processing)

ET total environmental impact related to transportation

TE total environmental impact

TTC total transport cost

TPC total production cost

TC total cost

\section{Research Methodology}

Given the gaps mentioned in the literature review, an integrated modeling approach is proposed in this study, which addresses the food supply chain consisting of production, distribution, and consumption activities more comprehensively about the COVID-19 epidemic. The concept of FHs has been used to connect consumers more efficiently and quickly to production sites. First, the food is brought from the production centers to the FHs, and then the FHs distribute the food to the small and large consumers. An MINLP mathematical planning model is proposed to reduce costs and environmental impacts.

In this paper, efforts have been made to reduce the spread of the virus as much as possible by designing an efficient supply chain. Therefore, two scenarios are considered. Areas covered by the food supply chain are divided into high-risk and low-risk areas. High-risk areas are more susceptible to the virus, and more people are infected.

In the first scenario, communication between high-risk and low-risk areas is not allowed. Low-risk (high-risk) areas should use products from their area or products from other low-risk (high-risk) areas. Each region must survive by relying on the food products of its region. These conditions are adjusted to minimize the prevalence of COVID19. Figure 1 shows the distribution of food in the first scenario. 
Figure 1 Food distribution problem of scenario 1

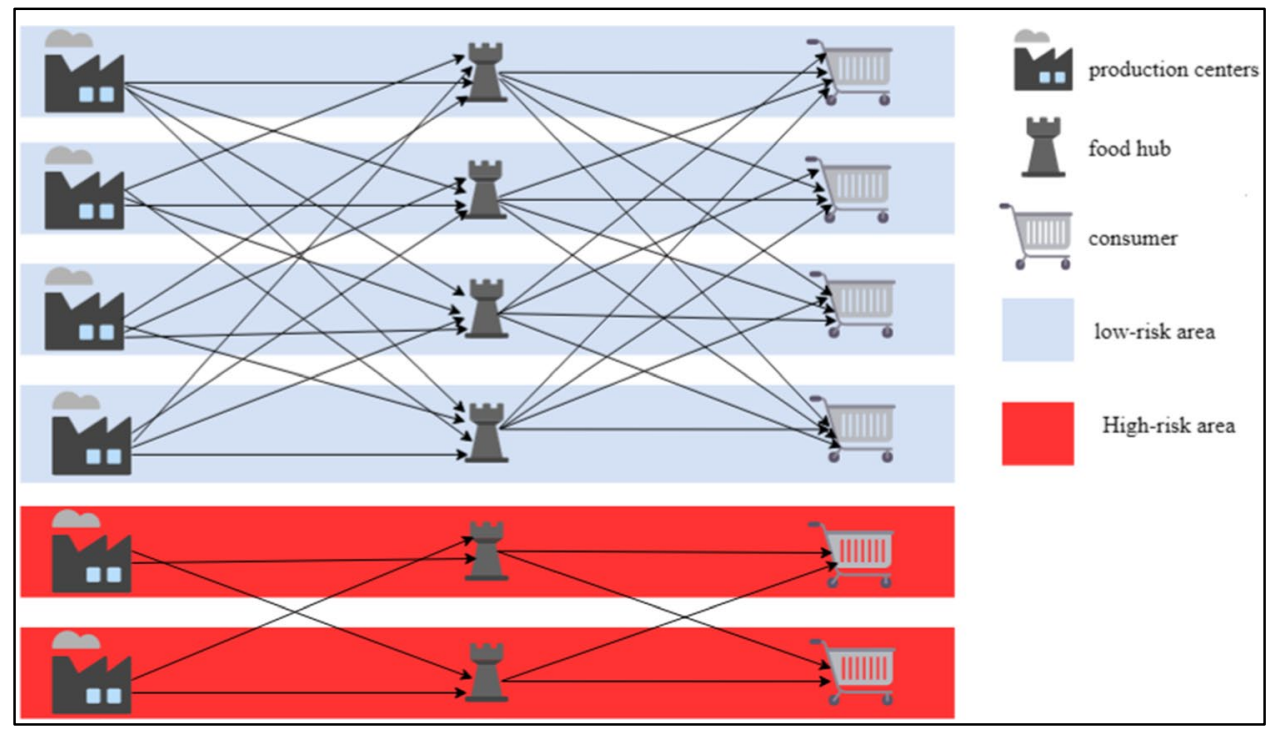

In the second scenario, a minor constraint is considered. Sending products from high-risk areas to low-risk areas is prohibited. But other areas can support high-risk areas, and sending food from low-risk areas to high-risk areas is allowed. These conditions are meant to decrease the spreading of COVID-19 from the high-risk areas to other areas. Figure 2 shows the distribution of food in the second scenario.

In both scenarios, it is determined how much product is brought from the production centers to the FHs of each region and how much is distributed among the consumers of each region. Cost is always an important factor in decisionmaking. Factors affecting costs are described in detail in the section "Model Validation." In this research, the cost and environmental damage of production and transportation of the product have been reduced as much as possible by examining these factors.

\section{Assumptions}

- All transports from production centers to FHs and from FHs to consumers are done by road and with one kind of truck.

- High-risk and low-risk areas have been identified based on expert opinions.

- In each region, one production center, one $\mathrm{FH}$, and one consumer are assumed.

- The products are in the packaging and the virus cannot infect them during transportation.

- Disinfection of the packaging is left to the customer.
Figure 2 Food distribution problem of scenario 2

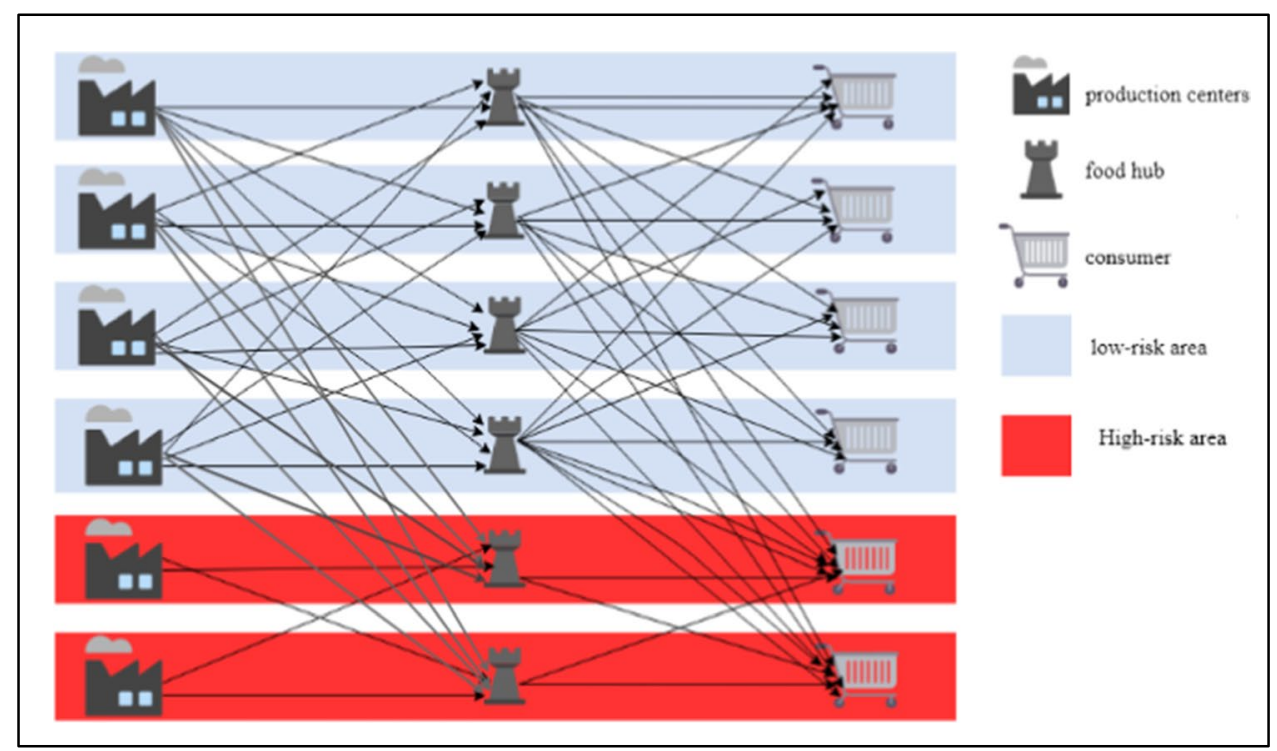




\section{Mathematical Model}

\section{Scenario 1}

In the first scenario, there is no connection between the lowrisk areas and high-risk areas. The low-risk (high-risk) area should use the products of its own area or the products of other low-risk (high-risk) areas.

The total cost function (first objective) for the network design problem is:

Minimize Obj1 $=T C=T P C+T T C$

(Tomans)

The total environmental impact (second objective) per indicator is given by:

Minimize $\operatorname{Obj} 2=T E=E T+E P$

$T T C=\sum_{i} \sum_{j} \sum_{p} c t_{u} * d i s t_{i j} u_{i j p}+\sum_{j} \sum_{l} \sum_{p} c t_{y} * \mathrm{int}_{j l} y_{j l p}$

$T P C=\sum_{i} \sum_{p} c p_{i p} x_{i p}$

The specific environmental impact functions are given by the following:

$E T=\sum_{i} \sum_{j} \sum_{p} e t * \operatorname{dist}_{i j} u_{i j p}+\sum_{j} \sum_{l} \sum_{p} e t *$ int $_{j l} y_{j l p}$

$E P_{h}=\sum_{i} \sum_{p} e p_{i p} x_{i p}$

The amount sent from the $\mathrm{FH}$ to the consumer is greater than or equal to the demand of product:

$d_{p j} \leq \sum_{l} y_{j l p} \forall j, p$

The amount of product sent to $\mathrm{FH}$ from the production zone is greater than or equal to the amount of product sent from $\mathrm{FH}$ to the consumer:

$\sum_{i} \sum_{p} u_{i j p} \geq \sum_{l} \sum_{p} y_{j l p} \forall j$

No food should be distributed from high-risk areas to low-risk areas:

$u_{r j p}=0 \forall j \in S-r$

No food should be distributed from low-risk areas to high-risk areas:

$u_{i r p}=0 \forall i \in S-r$

The amount of product produced is greater than or equal to the amount of product sent to $\mathrm{FH}$ : $\sum_{j} u_{i j p} \leq x_{i p} \forall i . p$

The gap between the right-hand and left-hand sides is the amount of product $\mathrm{p}$ wasted at the production zone.

$\sum_{i} x_{i p} \geq \sum_{i} d_{p i} \forall p$

Production capacity must be greater than or equal to the production and the quantity sent to the $\mathrm{FH}$ :

$\sum_{p} f_{p i} \geq \sum_{p} x_{i p} \forall i$

$\sum_{p} f_{p i} \geq \sum_{j} \sum_{p} u_{i j p} \forall i$

The capacity of the FH must be greater than or equal to the amount of input and output:

$S_{p j} \geq \sum_{l} y_{j l p} \forall j \cdot p$

$S_{p j} \geq \sum_{i} u_{i j p} \forall j . p$

\section{Scenario 2}

In the second scenario, low-risk areas can send products to the high-risk areas, but sending from the high-risk areas to the low-risk areas is not allowed. As we explained in the "Research Methodology" section, in this scenario, we have all the equations except eq. 13.

\section{Solution Methods}

To evaluate the model's performance, the problem is solved in small, medium, and large sizes. To solve the problem in small and medium sizes, exact methods are used by GAMS software. Solving large-size problems with accurate methods is time-consuming due to the high complexity, so accurate methods do not work well. Hence, meta-heuristics methods are employed for solving large-size optimization models. In this study, a genetic algorithm is used, which is one of the meta-heuristic methods. The performance of this algorithm is examined and the augmented $\varepsilon$-constraint approach is used to solve the developed linear multi-objective model.

\section{Multi-objective Method}

In multi-objective optimization to obtain Pareto solutions, several famous solving procedures such as goal programming, Lp-metrics, weighted sum, lexicographic, and epsilon-constraint are well-known (Abazari et al. 2020). In this paper, it is preferred to implement an improved version of the epsilon-constraint name as augmented epsilon-constraint. 
Several reasons prove that this method suits the proposed model. First, for the linear problems, augmented epsilonconstraint will obtain non-extreme efficient solutions, while the methods that contain weights produce only extra efficient solutions. Furthermore, in the proposed method, the scaling of the objective functions is not a problem; on the contrary, in weighting methods, it is necessary. Besides, finding the best weights is a time-consuming action that makes it harder to use goal programming. In addition, it is one of the posterior methods utilized to a multi-objective integer programming problem and can generate the exact Pareto set provided that the step size is appropriately chosen (Moghadam et al. 2021). Therefore, the augmented epsilon-constraint method has been implemented (Mavrotas and Florios 2013). The general form of the epsilon-constraint method solves the problems according to the Eq. (17).

$\min \mathrm{f}_{1}(x)$

$\mathrm{f}_{2}(x) \leq \varepsilon_{2}$

$\mathrm{f}_{3}(x) \leq \varepsilon_{3}$
It is important to note that the payoff matrix calculates the value of $(\varepsilon)$ represents the procedure of the proposed algorithm to obtain the Pareto solutions. By using augmented epsilon-constraint, the dominated optimal solutions can be eliminated from final Pareto solutions (Amin and Zhang 2013). Figure 3 shows the procedure of the proposed augmented epsilon-constraint.

\section{Genetic Optimization Algorithm}

Genetic algorithms are one of random search algorithms whose idea is derived from nature. In genetic algorithms, the first several answers are generated randomly or algorithmically. This set of answers is called the initial population. Each solution is called a chromosome. Initially, several attributes are randomly generated to create the first generation. For each individual, a parent pair is selected. There are several different patterns for selecting chromosomes. In this article, the roulette wheel pattern is used. Chromosomes recombine with a certain probability. From the combination of two chromosomes, a child is created that is transferred to
Figure 3 The procedure of the proposed augmented epsilonconstraint

\section{A) Generate Pareto solutions}

1- Solve the first objective function ( OBJ1 $=\mathrm{Z1} 1^{*}$ )

2 - Solve the second objective function $\left(\mathrm{OBJ} 2=\mathrm{Z} 2^{*}\right)$ with the constraint $\left(\mathrm{OBJ} 1=\mathrm{Z1} 1^{*}\right)$

3-Repeat step 1,2 to obtain payoff table
1- Discover the feasible solutions range of the objective functions from the previous step 2 - Divide feasible solution into evenly distributed intervals $(\varepsilon)$

\section{C) Generate Pareto solutions}

1- Solve the problem with the founded value of $(\varepsilon)$

2- Generate Pareto solutions 
the next generation. In the next step, with a probability of 0.02 , the child's chromosomes change or mutate randomly. This process creates a new generation of chromosomes, which is different from the previous generation. The whole process is repeated for the next generation, pairs are selected for the combination, a third-generation population is created, and this process is repeated until we reach the final stage.

\section{Numerical Examples}

\section{Computational Experiment}

In the small size problem, six areas have been considered that two of them are high-risk, and in the middle-size problem, ten areas have been considered that four of them are high-risk. The large size problem is created by increasing the number of areas and the amount of demand in each area and makes solving with exact methods by GAMS software time-consuming. To solve the large size problem, the genetic algorithm and MATLAB software have been used. Also, to solve the problems, an AMD Corei5 laptop with a frequency of $2.30 \mathrm{GHz}$ and $8 \mathrm{~GB}$ of RAM in the MATLAB R2014b has been used. All kinds of problems have been solved by considering one product. The parameters are presented in Tables 1 and 2 to solve in small and middle size.

\section{Model Validation}

In this section, to confirm the proposed model's performance, some parameters that affect the performance of the objective function, as expected, have been changed. For example, if the distances between the production centers and FHs are increased, the first and second objective functions' value increases. Because distances directly affect the cost and environmental effects, Figure 4 shows the effect of distance on objective functions. Other parameters that directly influence the performance of the objective function are the cost of transportation and the cost of product production. These two factors affect the first objective function and do not affect the second function. Figure 5 shows the effect of cost on functions.

\section{Results}

The amount of objective functions gained from solving the small-size problem is given in Table 3. In the second scenario, it is possible to send from low-risk to high-risk areas, but due to the distance between areas, it is preferable to take the product from the same areas close to each area, so the values of the objective functions of the first and second scenarios of small-size problem that are solved with GAMS software are equal.
Table 1 The assumed value of the model's parameters for the small size of the problem

\begin{tabular}{llllllllll}
\hline Parameter & Value & Parameter & Value & Parameter & Value & Parameter & Value & Parameter & Value \\
\hline$c t_{u}$ & 50 & $f_{5}$ & 816 & $d_{5}$ & 332 & $s_{5}$ & 1070 & $c_{5}$ & 33000 \\
$c t_{y}$ & 60 & $f_{6}$ & 548 & $d_{6}$ & 314 & $s_{6}$ & 1166 & $c_{6}$ & 21000 \\
$f_{1}$ & 908 & $d_{1}$ & 409 & $s_{1}$ & 10130 & $c_{1}$ & 19000 & $e t$ & 5.2 \\
$f_{2}$ & 953 & $d_{2}$ & 295 & $s_{2}$ & 1051 & $c_{2}$ & 29000 & $e p_{1}$ & 6.7 \\
$f_{3}$ & 963 & $d_{3}$ & 486 & $s_{3}$ & 1123 & $c_{3}$ & 28000 & $e p_{2}$ & 6.5 \\
$f_{4}$ & 957 & $d_{4}$ & 210 & $s_{4}$ & 1095 & $c_{4}$ & 26000 & $e p_{3}$ & 6.4 \\
$e p_{4}$ & 6.9 & $e p_{5}$ & 6.3 & $e p_{6}$ & 6.4 & & & & \\
\hline
\end{tabular}

Table 2 Assumed value of model's parameters for middle size of the problem

\begin{tabular}{llllllllll}
\hline Parameter & Value & Parameter & Value & Parameter & Value & Parameter & Value & Parameter & Value \\
\hline$f_{1}$ & 1022 & $f_{9}$ & 1853 & $d_{7}$ & 633 & $s_{5}$ & 2060 & $c_{3}$ & 26670 \\
$f_{2}$ & 939 & $f_{10}$ & 1163 & $d_{8}$ & 795 & $s_{6}$ & 2915 & $c_{4}$ & 29132 \\
$f_{3}$ & 1428 & $d_{1}$ & 749 & $d_{9}$ & 615 & $s_{7}$ & 2090 & $c_{5}$ & 30336 \\
$f_{4}$ & 1718 & $d_{2}$ & 746 & $d_{10}$ & 781 & $s_{8}$ & 2421 & $c_{6}$ & 22606 \\
$f_{5}$ & 1433 & $d_{3}$ & 781 & $s_{1}$ & 2317 & $s_{9}$ & 3460 & $c_{7}$ & 22639 \\
$f_{6}$ & 1355 & $d_{4}$ & 655 & $s_{2}$ & 2721 & $s_{10}$ & 2287 & $c_{8}$ & 25853 \\
$f_{7}$ & 1575 & $d_{5}$ & 788 & $s_{3}$ & 3145 & $c_{1}$ & 22659 & $c_{9}$ & 31429 \\
$f_{8}$ & 1251 & $d_{6}$ & 747 & $s_{4}$ & 2080 & $c_{2}$ & 30074 & $c_{10}$ & 32506 \\
\hline
\end{tabular}




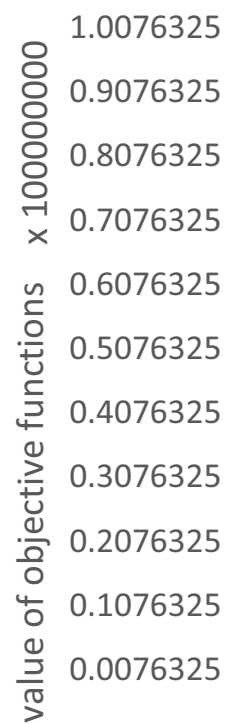

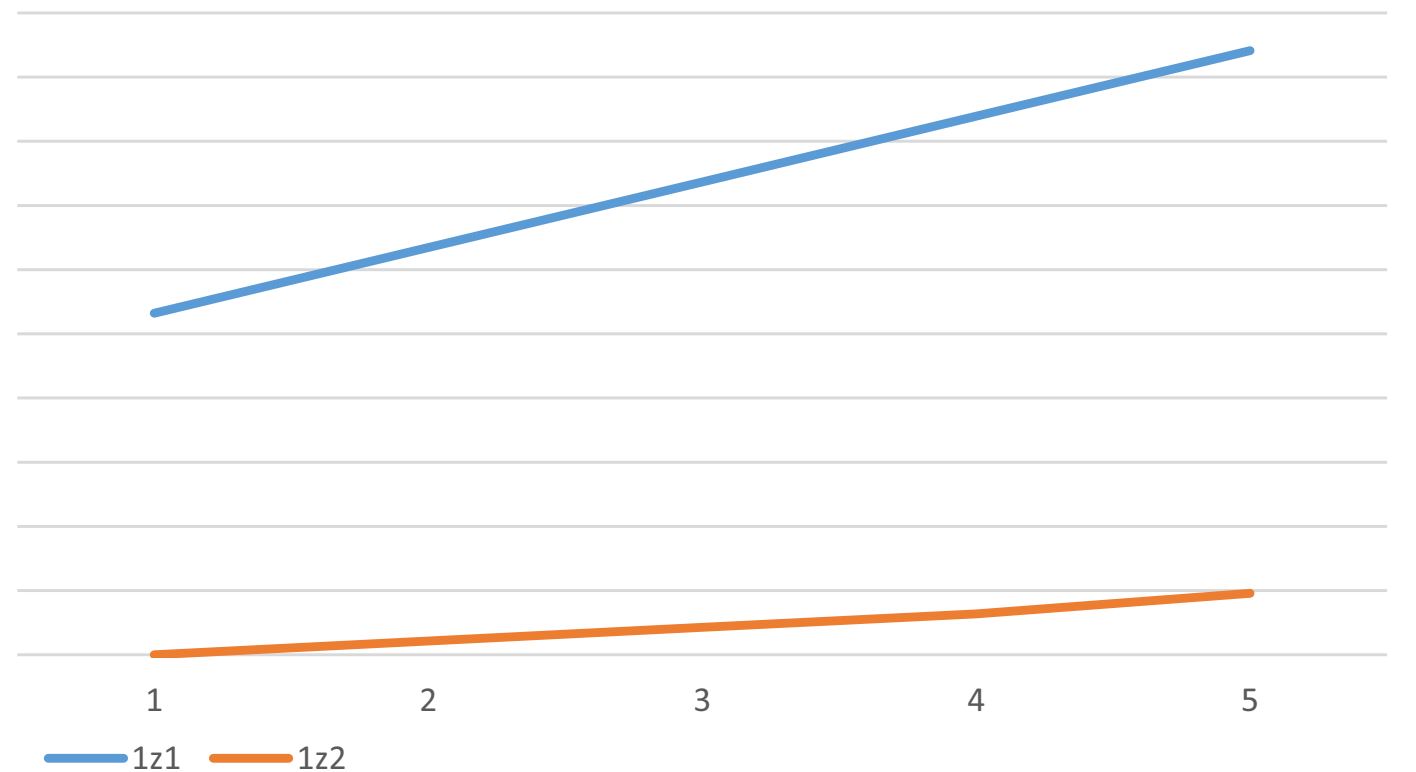

Figure 4 The effect of increasing distance on the objective functions

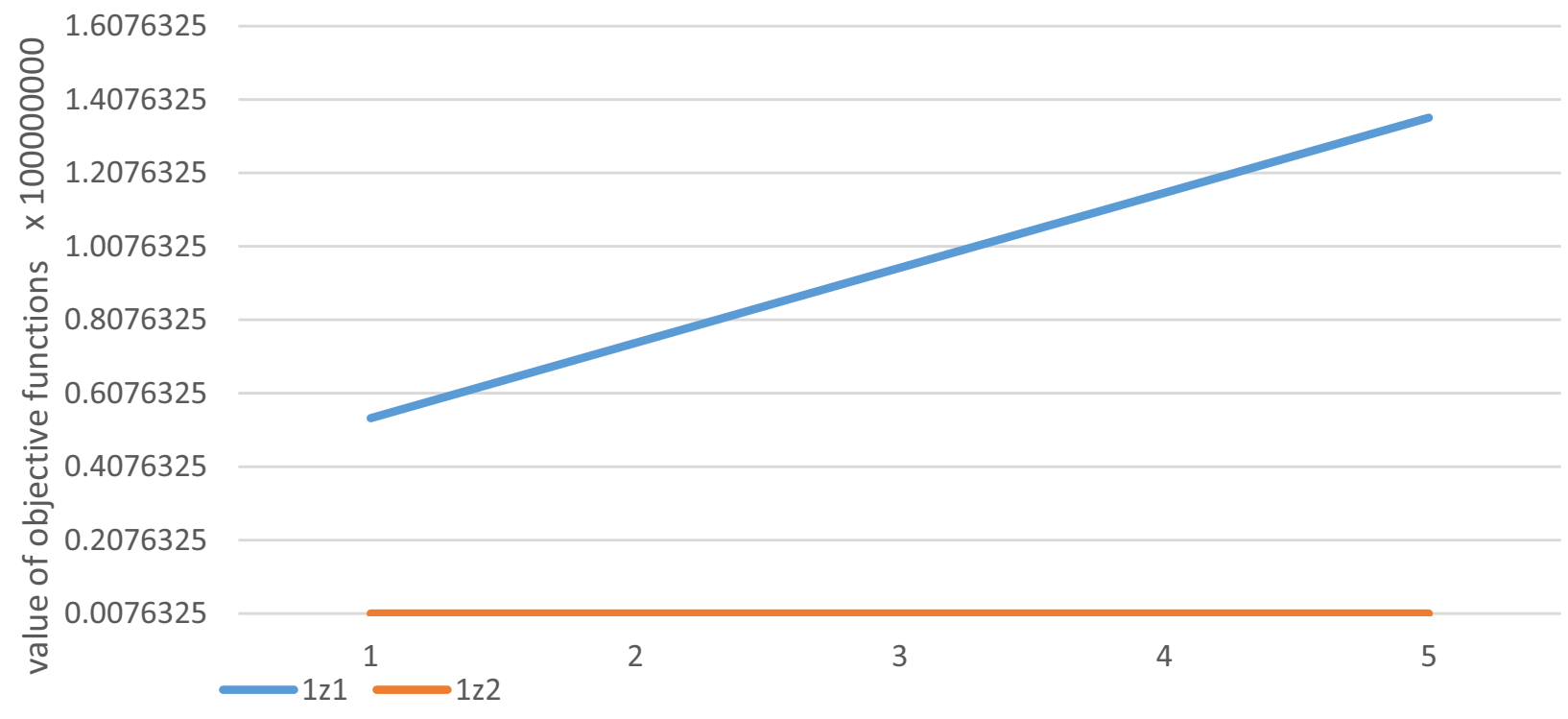

Figure 5 The effect of increasing cost on the objective functions

Table 3 The result of solving the small size problem

\begin{tabular}{llllll}
\hline & \multicolumn{2}{l}{ First scenario } & & & \multicolumn{2}{l}{ Second scenario } & \\
\cline { 2 - 3 } \cline { 5 - 6 } & GAMS & GA & & GAMS & GA \\
\hline OF1 & $5.3974360 * 107$ & $5.486379078 * 10^{7}$ & & $5.3974360^{*} 10^{7}$ & $5.453296418^{*} * 10^{7}$ \\
OF2 & $7.632534 * 10^{5}$ & $7.632534055 * 10^{5}$ & & $7.632534 * 10^{5}$ & $7.632534376^{*} 10^{5}$ \\
\hline
\end{tabular}


The results of solving the small- and middle-size problem for the first scenario of objective function 1 with GAMS software are given in Tables 4 and 5 .

The results of the small size problem for the first objective function of scenario 1 with the GA have been illustrated in Table 6. Also, convergence diagrams GA to optimal solutions for objective function 1 of scenario 1 of small- and middle-size problem are indicated in Figures 6 and 7.

It seems that there is no significant difference between the value of the objective function of the genetic algorithm and GAMS software. So, the genetic algorithm works properly. A statistical model is given in Appendix. This statistical model tests the hypothesis of equality of the objective function's value with a genetic algorithm and GAMS software. And it seems that there is no significant difference between the results, and the null hypothesis is accepted. So, the genetic algorithm can be used to solve the large-size problem. In the large-size problem, 20 areas have been considered, which there are 7 high-risk areas. Its convergence diagram for the first objective function is shown in Figure 8. In the first scenario, the value of the first and second objective functions are $2.795 * 10^{9}$ and $1.047 * 10^{9}$.

Figure 9 shows the Pareto solutions. The total number of Pareto solutions is 491 different values. The best value for the first objective function is $5.3974360 * 10^{7}$, while the second objective function is $8.30217 * 10^{5}$. On the other hand, the best value of the second objective function is
$7.632534 * 10^{5}$, while the first one is $6.4854320 * 10^{7}$. the payoff table of the problem is given in Table 7 .

\section{Sensitive Analysis}

Parameter analysis leads to a better understanding of the model. In each series, the value of the examined parameters will increase or decrease. First, the analysis on the demand parameter has been performed. As demand increases, the first objective function's values increase because more products must be shipped between the production center and FHs and from FHs to the consumer, and the cost increases. Figure 10 shows the increase of the first objective function in return for the increase in demand in each series. When demand increases, the production volume increases, but not necessarily the amount of production in all regions. Additional demand for low-risk or high-risk areas can be met from other areas under the limitation stated earlier. This limited communication reduces the spread of the virus. Figure 11 shows the effect of increased demand in each series on the production of each region. Figure 12 shows that the fourth and fifth regions support the increase in demand in the sixth region.

As demand increases, the second objective function must also increase because of the destructive environmental effects of production and transportation increase. Figure 13 shows the effect of increasing demand on the second objective function. In the second objective function, attempts have been made to reduce the environmental impact, and
Table 4 Small model's results for scenario 1 of $\mathrm{OF} 1$ with GAMS software

\begin{tabular}{llllllllll}
\hline Variable & Value & Variable & Value & Variable & Value & Variable & Value & Variable & Value \\
\hline$y_{11}$ & 409 & $y_{44}$ & 210 & $y_{66}$ & 314 & $U_{43}$ & 486 & $x_{4}$ & 794 \\
$y_{22}$ & 295 & $y_{45}$ & 98 & $U_{11}$ & 409 & $U_{44}$ & 308 & $x_{6}$ & 548 \\
$y_{33}$ & 486 & $y_{65}$ & 234 & $U_{12}$ & 295 & $U_{66}$ & 548 & $x_{1}$ & 704 \\
\hline
\end{tabular}

Table 5 Middle model's results for scenario 1 of $\mathrm{OF} 1$ with GAMS software

Table 6 Small model's results for scenario 1 of OF1 with GA

\begin{tabular}{llllllllll}
\hline Variable & Value & Variable & Value & Variable & Value & Variable & Value & Variable & Value \\
\hline$y_{11}$ & 749 & $y_{55}$ & 788 & $y_{810}$ & 781 & $U_{66}$ & 745 & $x_{3}$ & 1428 \\
$y_{12}$ & 273 & $y_{45}$ & 98 & $U_{11}$ & 1022 & $U_{77}$ & 635 & $x_{4}$ & 481 \\
$y_{32}$ & 473 & $y_{66}$ & 745 & $U_{33}$ & 1428 & $U_{78}$ & 325 & $x_{5}$ & 178 \\
$y_{31}$ & 781 & $y_{77}$ & 633 & $U_{44}$ & 481 & $U_{79}$ & 615 & $x_{6}$ & 1355 \\
$y_{34}$ & 174 & $y_{88}$ & 795 & $U_{55}$ & 178 & $U_{88}$ & 1251 & $x_{7}$ & 1575 \\
$y_{44}$ & 481 & $y_{99}$ & 615 & $U_{65}$ & 610 & $x_{1}$ & 1022 & $x_{8}$ & 1251 \\
\hline
\end{tabular}

\begin{tabular}{llllllll}
\hline Variable & Value & Variable & Value & Variable & Value & Variable & Value \\
\hline$y_{11}$ & 409 & $U_{11}$ & 409 & $y_{66}$ & 314 & $x_{1}$ & 704 \\
$y_{22}$ & 295 & $U_{12}$ & 295 & $x_{6}$ & 547.9 & $y_{33}$ & 489 \\
$y_{44}$ & 210 & $U_{43}$ & 488 & $U_{44}$ & 312 & & \\
\hline
\end{tabular}




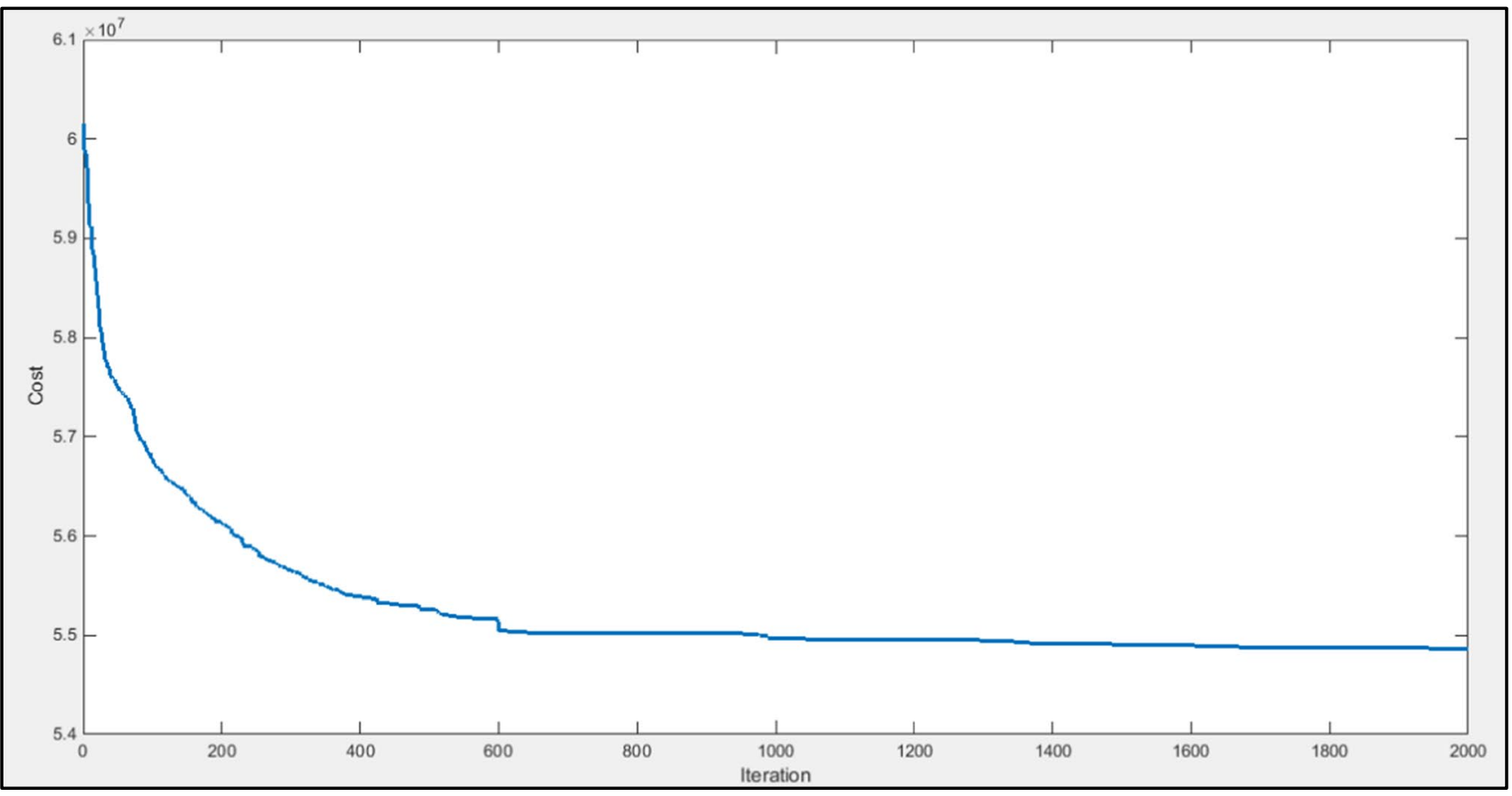

Figure 6 Convergence of GA to the optimal solution for small-size Of1 in scenario1

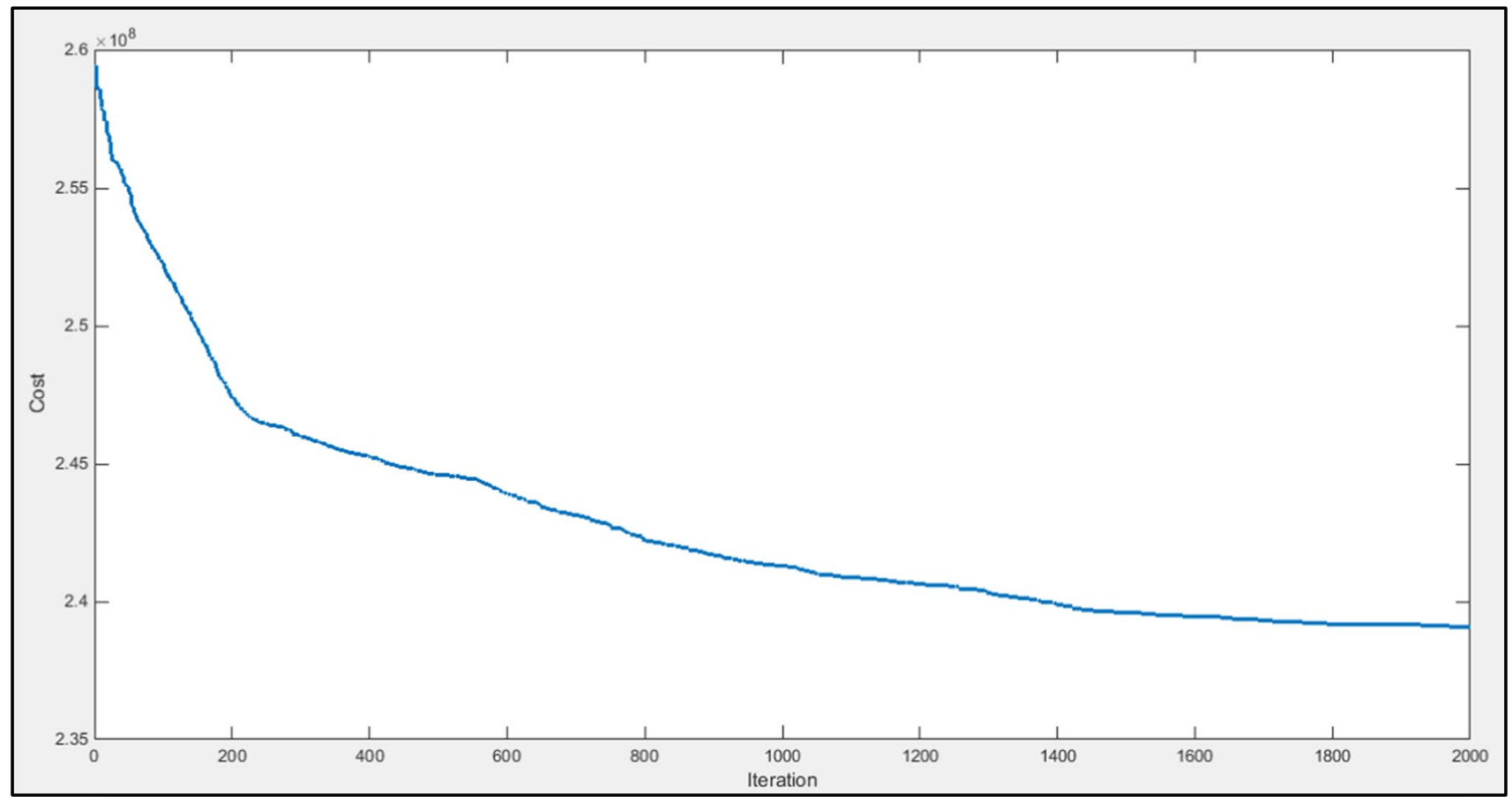

Figure 7 Convergence of GA to the optimal solution for middle-size Of1 in scenario1

these effects are due to the production and transportation of products. Therefore, as far as possible, each region meets its own additional demand or satisfies it from nearby regions (under the limitation). This has less detrimental effect on the environment than receiving products from other regions.

Figure 14 shows the increase in demand in each series and its effect on the amount of product sent from food hubs. 


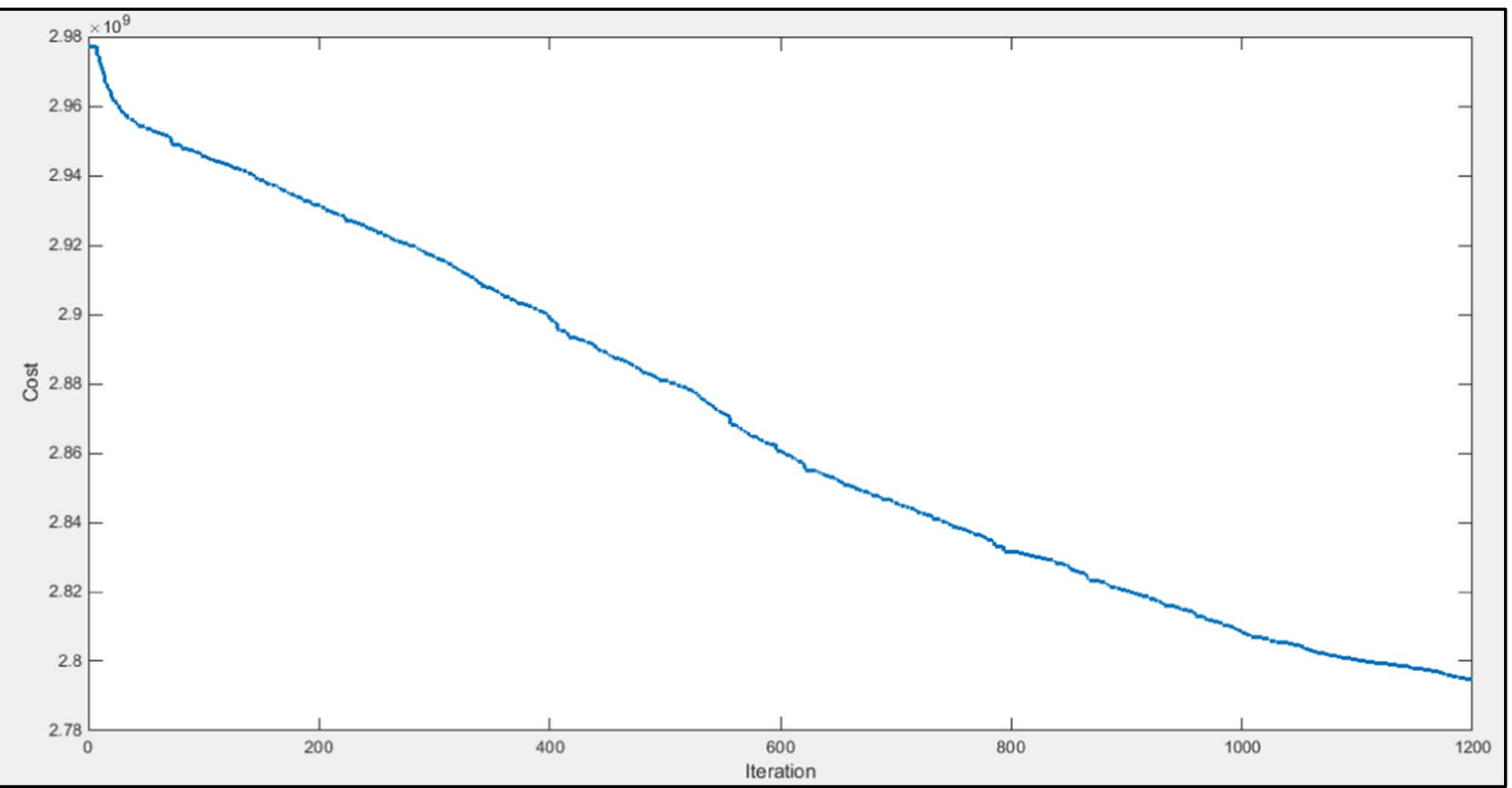

Figure 8 Convergence of GA to the optimal solution for the large size of the problem for OF1

Figure 9 Pareto solutions of the problem by augmented epsilonconstraint
Table 7 The payoff table of each objective function

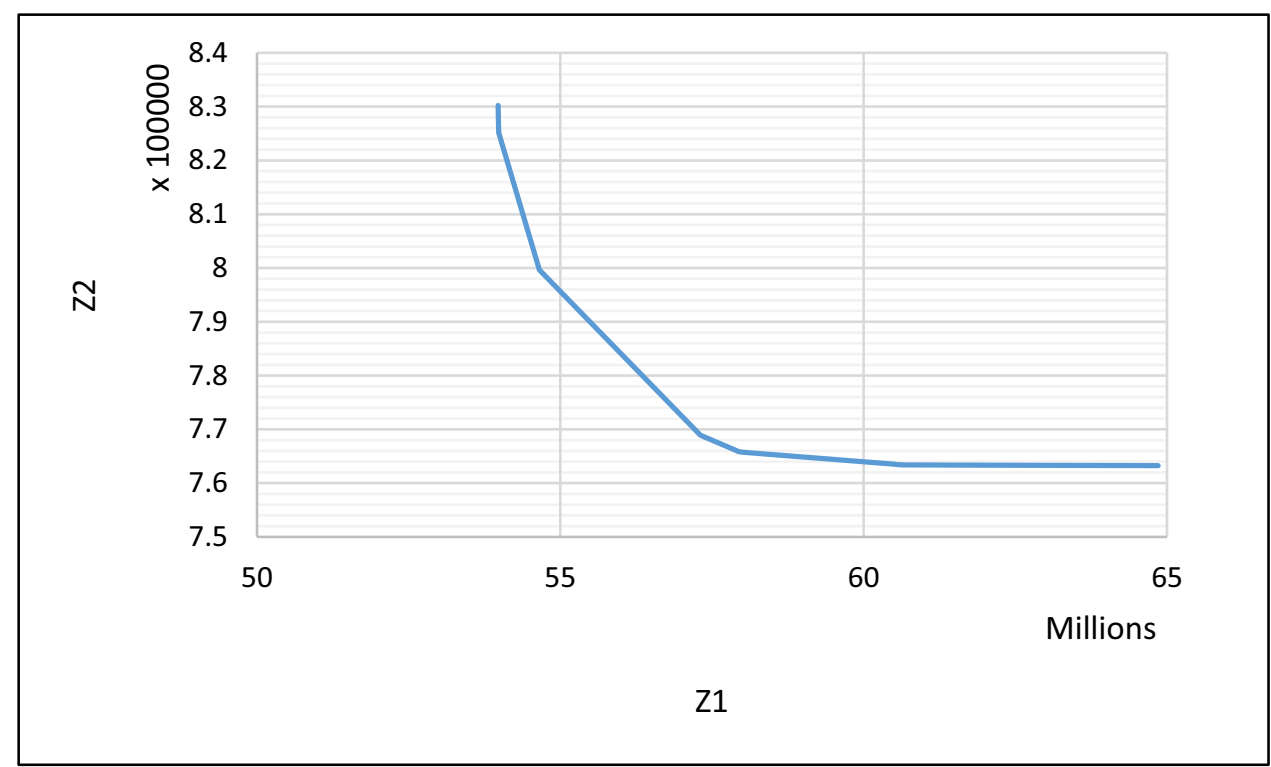

with each other). Also, the third area supplies its additional demand from the fourth area (assuming that the third and fourth area are the low-risk areas), Because the fourth area is closer to third area than other areas and has less destructive effect due to transportation. Despite the limited communication between the regions, in addition to reducing the spread of the virus, the demands of each region are also met.

As the production capacity increases, the value of the first objective function decreases because each region can meet its needs from closer regions or produce more or receive 
Figure 10 The effect of increasing demand on first objective function

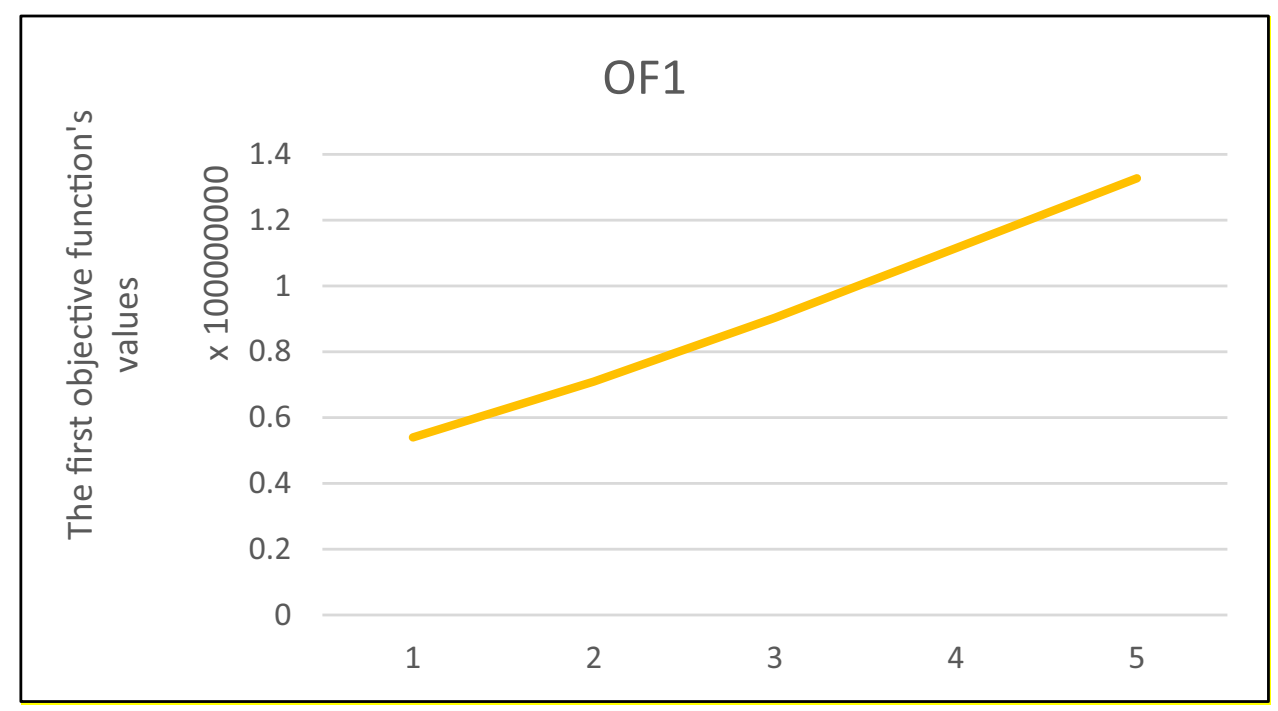

Figure 11 The demand has increased in each series and the amount of production in each region is marked

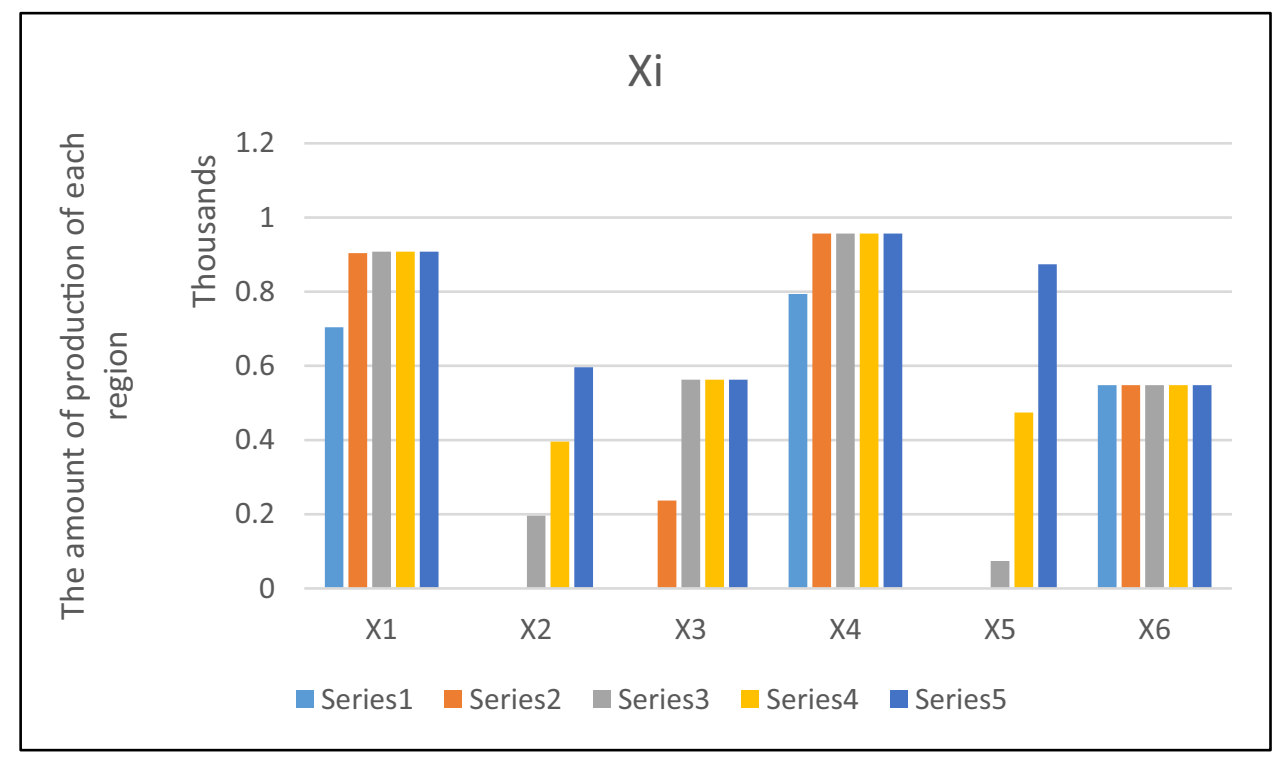

the product from regions whose production cost is lower. Figure 15 shows the effect of increasing production capacity on the first objective function. If only the first, fourth, or sixth regions produce, with the increase of production capacity, the amount of production of the first region will remain constant because it must supply only the product of its own region and the second region (assuming that the first region and the second region are high-risk areas and can only communicate with each other). The production of the sixth zone increases and has a more significant share in meeting the low-risk zones' needs. Because the cost of production in the sixth region is lower than the fourth region, it is preferable to produce in the sixth region instead of production in the fourth region. Therefore, with the increase of production capacity, the sixth region's production increases, and the fourth region's decreases. Figure 16 shows the effect of increasing production capacity on the amount of production in the regions. Since the first region only meets the demand of its own region and the second region and has no connection with other regions, it causes more control over the spread of the virus. In this case, there is no connection between low-risk and high-risk areas.

As the production capacity decreases, the value of the second objective function increases because some regions satisfy their demand from other regions. Also, more product is produced in some areas and transferred to other areas. The transfer of products between regions increases the destructive environmental effects of product transportation. Figure 17 shows the effect of reducing the production capacity on the second objective function and total environmental impact related to transportation (ET). Figure 18 shows the effect of reduced production capacity in each series on the 
Figure 12 The effect of increasing demand on the amount of food hub received in the sixth region

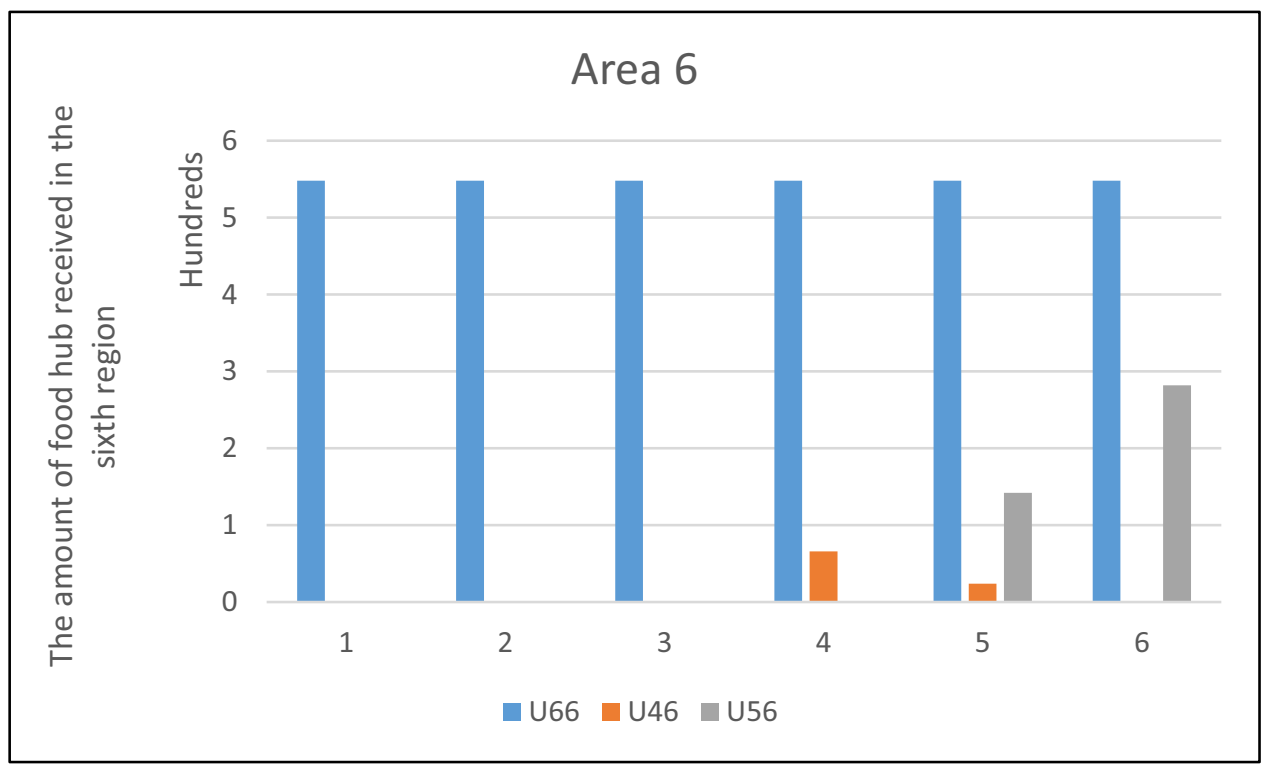

Figure 13 Impact of increasing demand on the second objective function

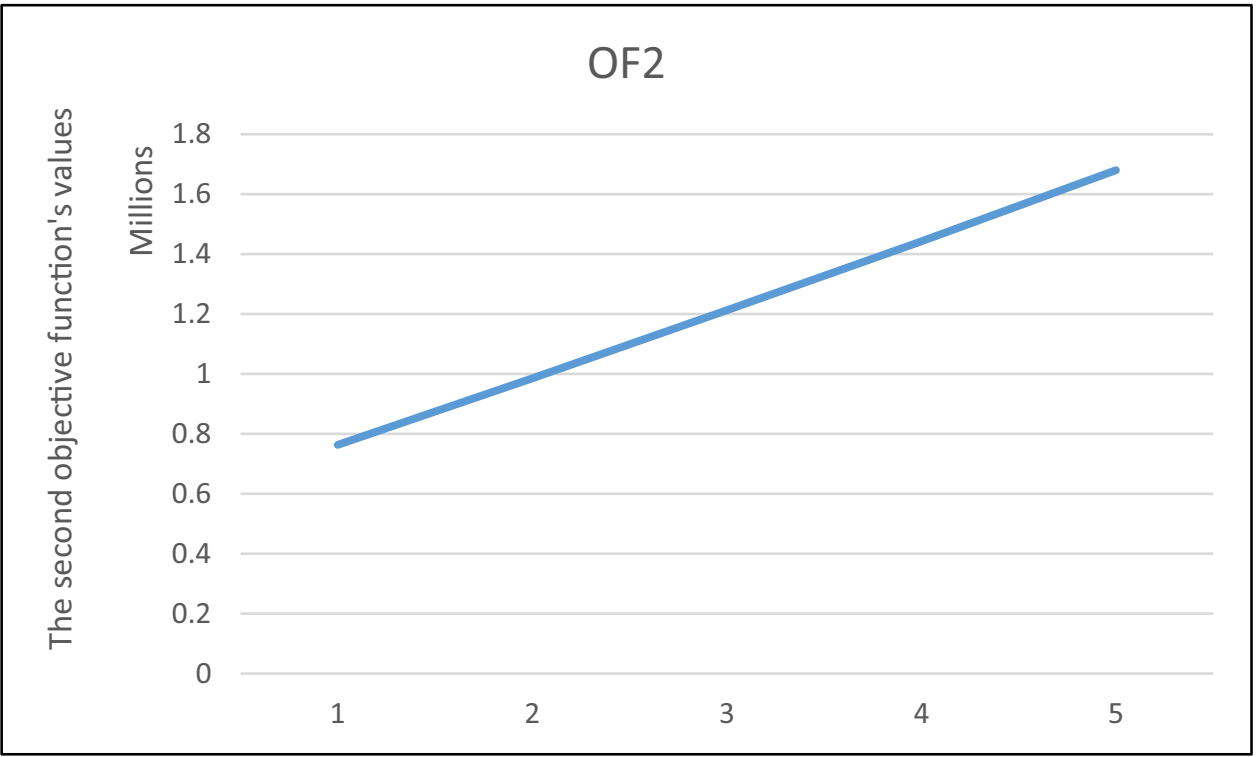

number of products sent from food production centers to the food hubs. For example, by reducing production capacity, the sixth region, which is a low-risk region, supplies part of its demand from another low-risk region, such as the fourth region. Because the fourth region is less distant than other regions with the sixth region and the destructive effects of transportation are less than the others. But in the fifth series, the production capacity is so reduced that the regions' demand is not fully met and becomes infeasible.

Although each scenario has different functions and is defined to reduce the spread of coronavirus, to compare the two scenarios, the value of the first objective functions in the second scenario is less than the first scenario. In the first scenario, there are more restrictions on the relationship between the regions, which causes the values of the objective function to increase. Figure 19 shows a comparison of the first objective functions in the first and second scenarios.

\section{Case Study}

As you know, the coronavirus has affected many countries and regions. Iran is one of the countries infected with coronavirus, which is ranked eighth in the world in terms of the number of deaths. In Iran, from December 2019 to September 2021, more than 5 million people 
Figure 14 The demand has increased in each series and the amount of products sent to the consumer from the food hub is marked
Figure 15 The effect of increasing production capacity on the first objective function
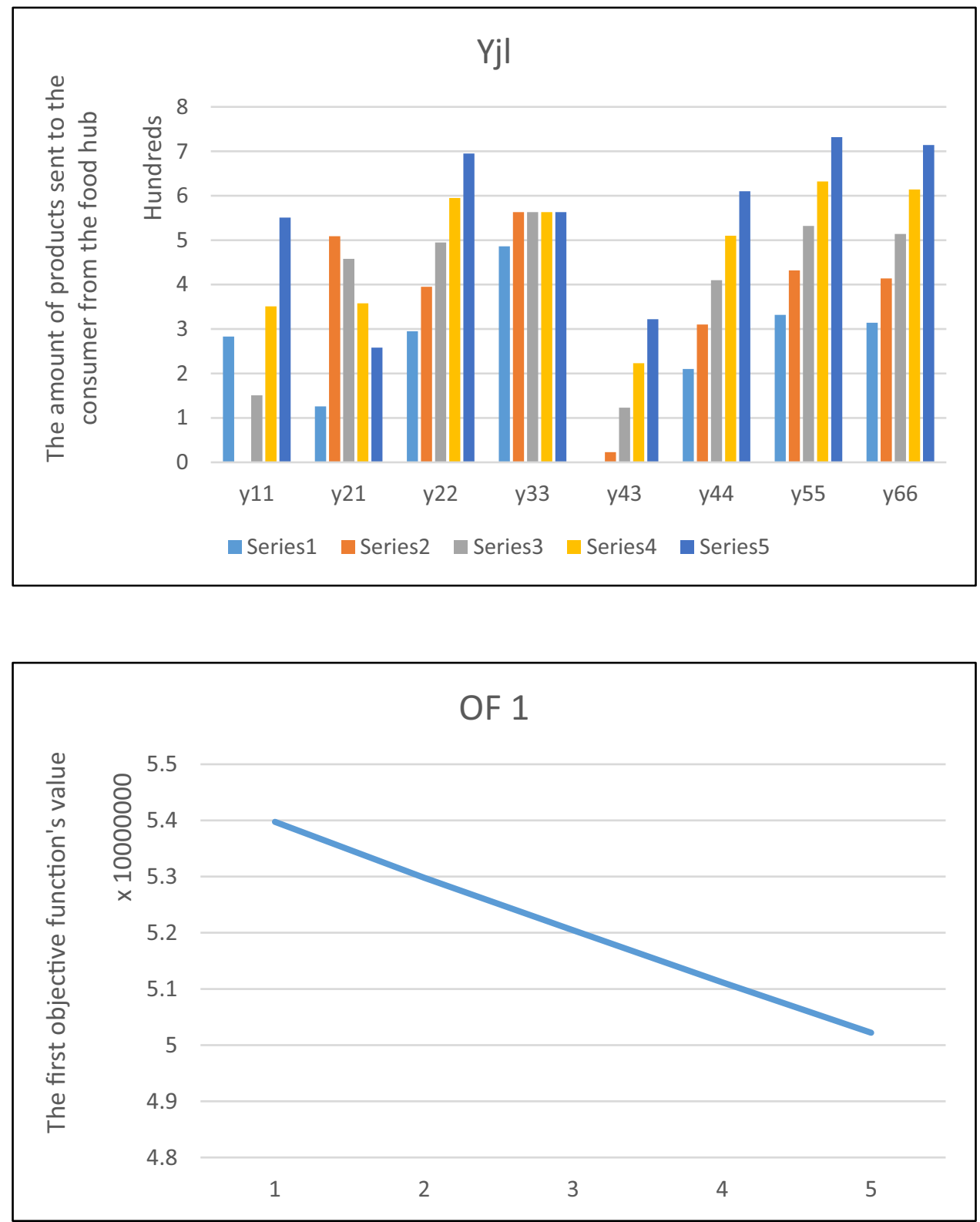

have been infected with the virus, and more than 118,000 people have died from the disease (world meters, 2021). The Iranian government determines the status of each city based on the number of people admitted to the hospital. Hospitalizations of four to ten people per 100,000 people identify low-risk cities, and hospitalizations of 10 people and more per 100,000 people determine high-risk cities. Accordingly, in this case study, four low-risk cities and two high-risk cities have been selected. Low-risk cities are Damavand, Pakdasht, Firoozkooh, and Varamin and high-risk cities are Tehran and Rey. Figure 20 shows the location of low-risk and high-risk cities. Low-risk cities are shown in green and high-risk cities in red.
In this case study, a production center, a food hub, and a consumer are considered in each area. Traveling distances are measured with Google Map's measure tool. Figure 21 shows the location of each production center, FHs, and consumer on the map. The product under study is beef. This choice is because this product has a high demand in the community, and almost all sections of society are consumers of it. Also, the type of production can have different impacts on the environment. The environmental impact data for production and transportation are taken from the Agri-footprint database (https://www.agri-footprint.com).

The market price of $1 \mathrm{~kg}$ of beef is 175,000 Tomans in Iran, and we estimate its production cost to be approximately 
Figure 16 The effect of increasing production capacity on the amount of production in the regions
Figure 17 The effect of decreasing production capacity on the second objective function
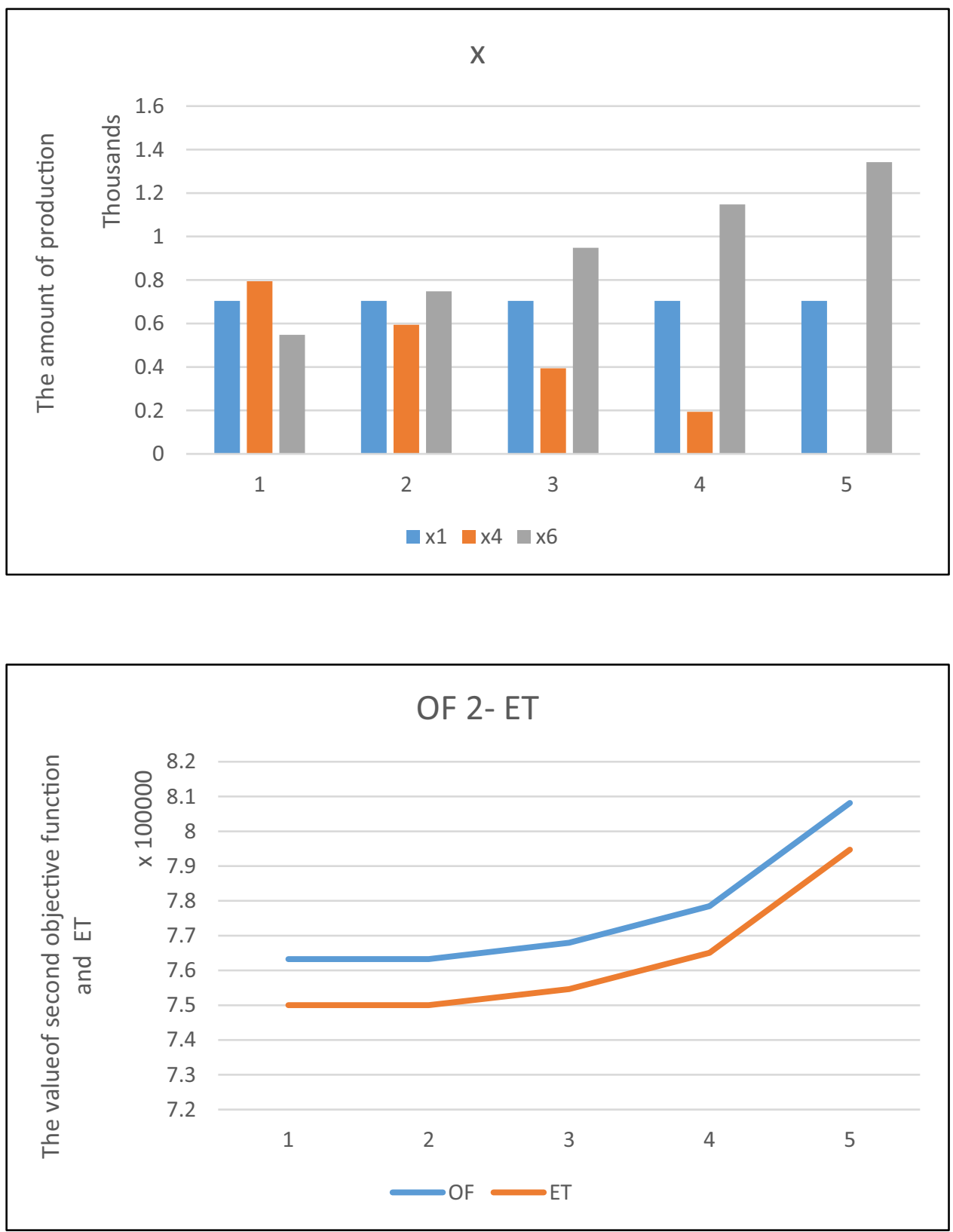

100,000 Tomans. The fuel cost in Iran is 3000 Tomans per liter, and the amount of fuel consumption of the considered trucks is about $0.33 \mathrm{~L} / \mathrm{km}$. Considering the cost of insurance, driver's rights, depreciation, etc., based on available data, the cost of transportation per kilometer is 10,000 tomans. Calculations are performed only for the first scenario.

In this case study, the first scenario is considered. The results of solving the model based on real data are shown in Tables 8 and 9 .

According to the results, production capacity in Tehran does not meet its own demand in the coronavirus epidemic. Therefore, additional demand has been met from other highrisk cities (Rey city). It is possible to increase the production capacity of this city by adding a production line and more costs. In this case, the destructive effects of the environment are reduced. Other low-risk cities can meet their own demand. Excess demand can also be offset from other lowrisk cities during the quarantine and panic consumption behaviors.

\section{Discussion and Managerial Insights}

This study focused on the corona epidemic. Since December 2019, the coronavirus has been affecting people all over the world. Although vaccination has begun in some parts 
Figure 18 The production capacity has decreased in products sent to the $\mathrm{FHj}$ from production center $\mathrm{i}$ is marked each series and the amount of

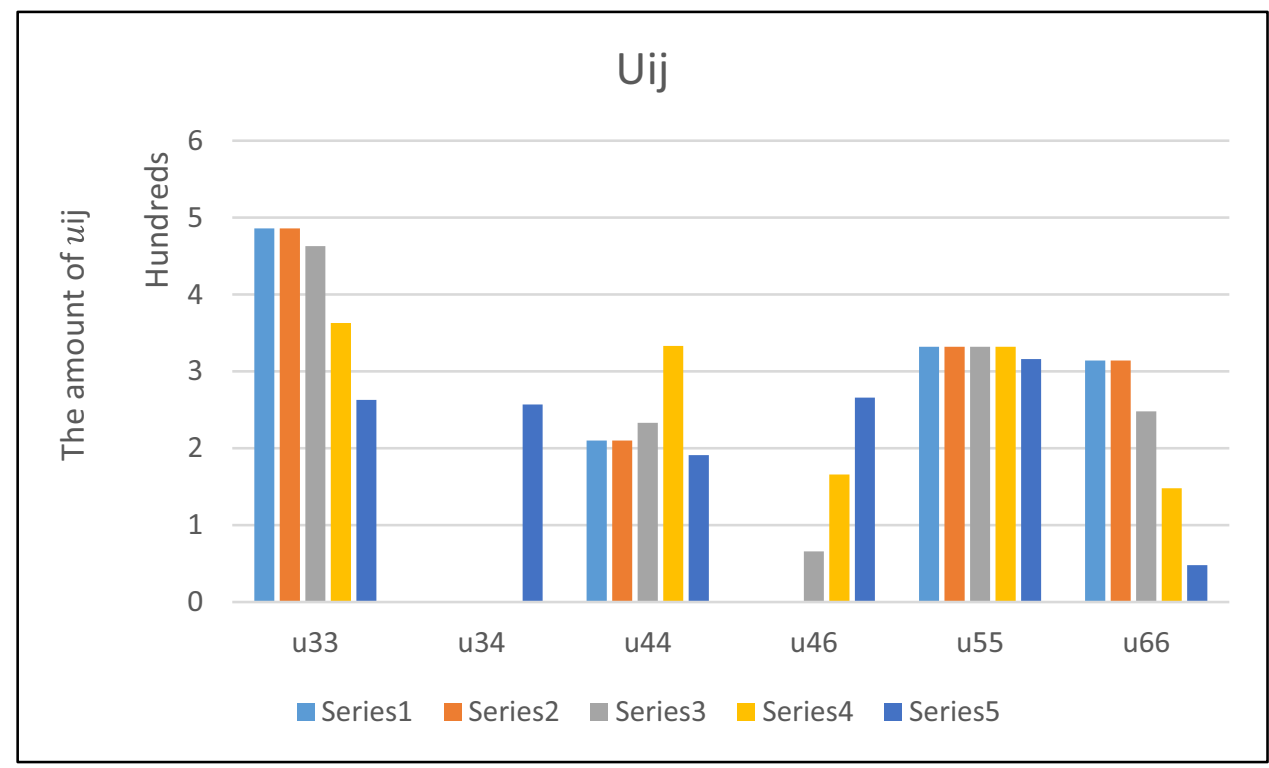

Figure 19 Comparison of the first and second scenarios for the first objective function

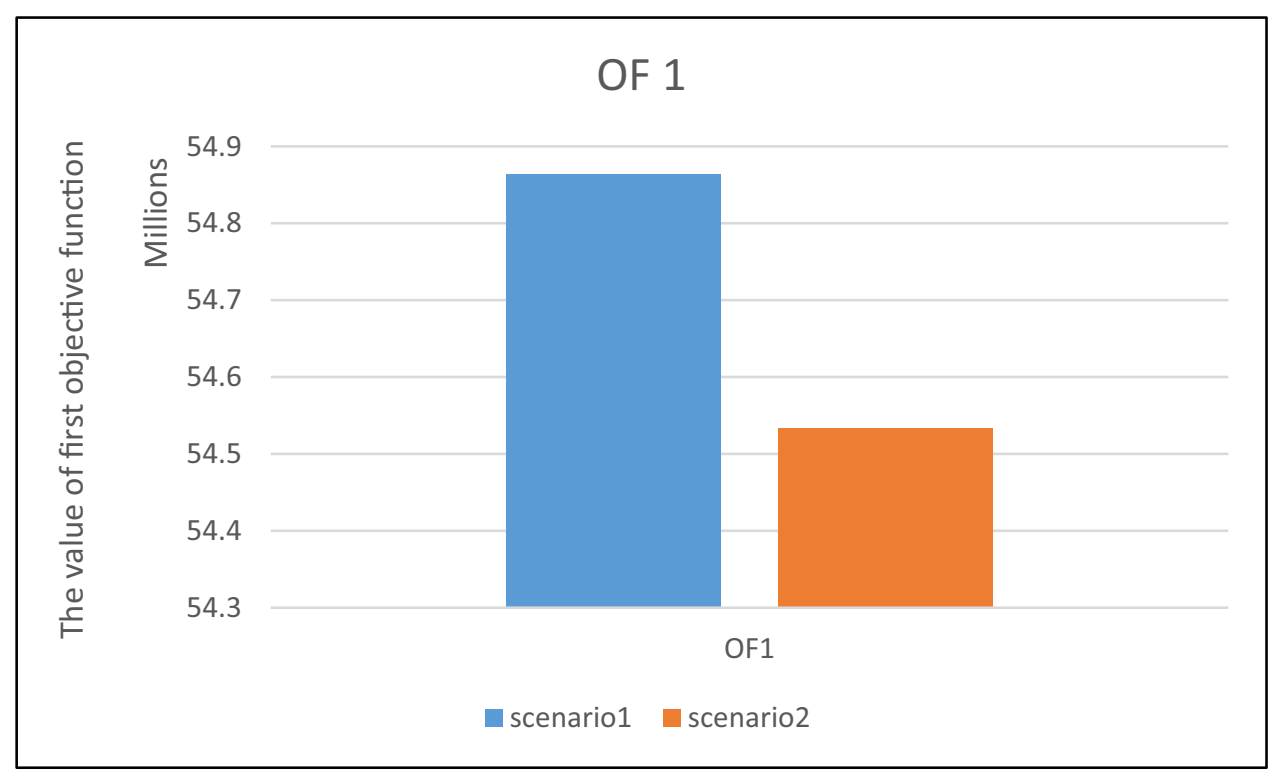

of the world, vaccination may continue for several years, and many people are deprived. Also, this pandemic is not the first pandemic ever and probably will not be the last. Therefore, the mathematical model has been presented in which the regions into two parts, high-risk and low-risk, have been divided. Two scenarios have been introduced that reduce the spread of the virus, and the mathematical model can be applied in the real world. In addition to economic factors, the environmental effects that lead to the transportation and production of products have also been considered and have been tried to reduce the environmental damage as much as possible. Also, Zabir et al. (2021) focused on the effects of COVID-19 on food shortages, and the unavailability of distribution channels. Grida et al. (2020) showed that demand under the influence of COVID-19 prevention policies had the greatest impact on the supply chain. Hobbs (2020) discussed the effects of demand shocks on food supply chains, including consumer panic behaviors about basic commodities. In this study, a way has been presented that all regions can meet their needs with the help of other regions, and demand changes in quarantine can be controlled to a very good extent. Rizou et al. (2020) summarize the possible transmission ways of the virus through the FCS. Also, it was stated above that they pointed out that the more we move to the final stages of the supply chain, the more people are involved in the process, and more action is taken. It is necessary to reduce the spread of the virus. In this study, a practical solution has been presented to reduce the spread of the virus at the macro level and limit the communication of the regions. Also it has been specified how much each 
Figure 20 The location of highrisk and low-risk cities
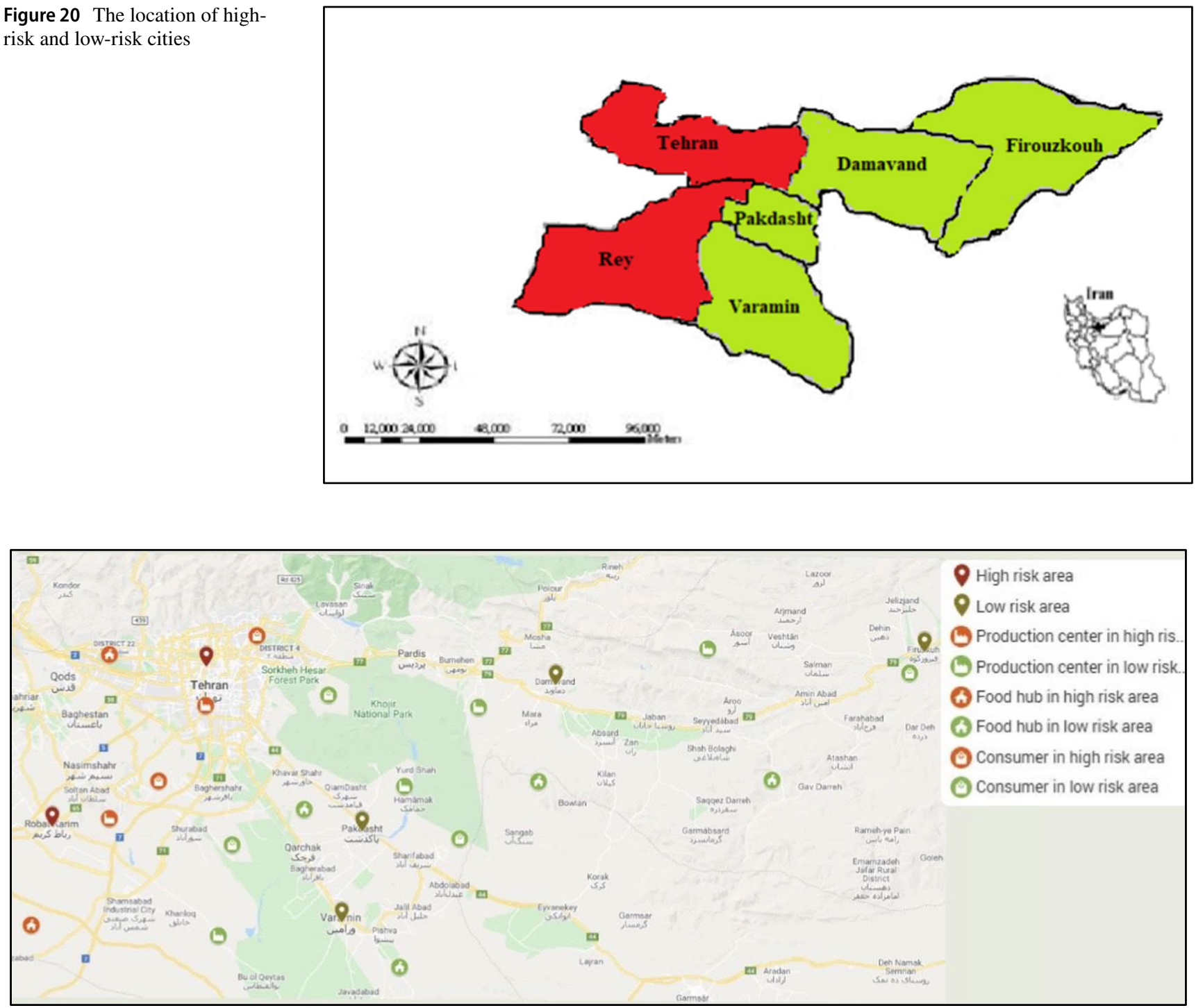

Figure 21 The location of production centers, FHs, and consumers

Table 8 The value of the objective function

\begin{tabular}{lll}
\hline & $\begin{array}{l}\text { Frist objective function } \\
\text { (Toman) }\end{array}$ & $\begin{array}{l}\text { Second objective function } \\
\left(\mathrm{m}^{3}\right)\end{array}$ \\
\hline Value & $118,046,842,412.3662$ & $53,584,391.2019$ \\
\hline
\end{tabular}

region produces and how much it sends to other regions according to demand. According to the sensitivity analysis, it has been determined that increasing demand in each region does not necessarily lead to increased production in that region, and other regions can justify the shortage. Therefore, by implementing this model at the macro level, in
Table 9 Model's results for scenario 1

\begin{tabular}{llllllllll}
\hline Variable & Value & Variable & Value & Variable & Value & Variable & Value & Variable & Value \\
\hline$y_{11}$ & 100,000 & $y_{44}$ & 7698.8 & $y_{66}$ & 2062.6 & $U_{44}$ & $20,043.5$ & $x_{4}$ & $20,043.5$ \\
$y_{21}$ & $43,630.3$ & $y_{55}$ & 551.63 & $U_{11}$ & 100,000 & $U_{55}$ & 551 & $x_{6}$ & 2062.6 \\
$y_{43}$ & $12,344.67$ & $y_{22}$ & 5748.4 & $U_{12}$ & $49,378.7$ & $U_{66}$ & 2062.6 & $x_{1}$ & 100,000 \\
$x_{2}$ & $49,378.7$ & $x_{5}$ & 551.6 & & & & & & \\
\hline
\end{tabular}


addition to reducing the spread of the virus, the occurrence of deficiencies during quarantine can be prevented. Based on Figure 12 in sensitive analysis section, if the economic dimension is more important, managers are advised that in a low-risk area, if the demand increases, they can supply additional demand from other low-risk areas that have lower production costs; otherwise, the amount of production must be increased in the same area, and based on Figure 14, if the environmental dimension is more important, they can supply additional demand from the same area or areas close to that area. In this case, less distance will be traveled, and it will have less destructive environmental effects.

Also, according to Figure 15, managers are advised that if they can add a production line to increase production capacity, they can reduce the total costs. According to Figure 16, if managers want to increase the production capacity of a region, it should be the sixth region, for example, by using new and high-efficiency technologies, because the cost of production in this region is lower than other low-risk areas and also meets the demand of other low-risk areas.

According to Figure 19, managers are advised that if the spread of the virus has intensified, they can implement the first scenario in areas covered by the supply chain at higher costs. In this case, the communication between low-risk and high-risk areas is limited, and the spread of the virus is reduced. But if the economic dimension is more important, they can implement the second scenario. Therefore, by implementing the model in real conditions, managers are helped to make decisions about reducing virus spread or reducing costs.

\section{Conclusion and Future Study}

In this research, a multi-objective MINLP model has been presented to reduce production and transportation costs and destructive environmental effects. The areas covered by the supply chain have been divided into two parts, high-risk and low-risk areas, and two scenarios have been defined that limit the connection between low-risk and high-risk areas and prevent the spread of the coronavirus. To evaluate the model's performance, the problem has been considered in small, medium, and large sizes that small-size and mediumsize problems have been solved with a precise method by GAMS software. Then, using the genetic algorithm, the small- and medium-size problems have been evaluated. The results showed that there is no significant difference between results with accurate method by GAMS software and metaheuristic method. Also, the first scenario was implemented in real conditions in Iran, and high-risk and low-risk cities were selected based on expert opinion. It was determined how much of the product was to be sent to each area to minimize the cost and environmental impact. As a result, a genetic algorithm has been used to solve the large size problem. An improved version of the epsilon-constraint name as augmented epsilon-constraint has been presented and given the decision-makers the freedom to choose between the objective's values according to the situation and their preferences. Also, the results were showed by implementing the model in real conditions; it can be decided whether to reduce the spread of the virus or reduce costs. If the spread of the virus is intensified, the first scenario can be implemented at a higher cost, and if the economic dimension is more important, the second scenario can be replaced. During the corona epidemic, by increasing demand and panic consumption behaviors, if the economic dimension is important, it can be compensated from low-risk areas at a lower cost, and if the environmental dimension is more important, additional demand can be met from nearby areas. In future research, despite the quarantine in the world, and the desire of people to buy on the Internet for each high-risk and low-risk area, the distribution and delivery to the consumer by online shopping, besides existing methods, can be considered. In this paper, it is assumed that according to the opinions of experts, high-risk and low-risk areas have been identified. but in future research, it is suggested that low-risk and highrisk areas be identified using methods such as multi-attribute decision-making (MADM).

\section{Appendix}

In this section, the hypothesis is evaluated of equality of target functions of the genetic algorithm and GAMS software. Therefore, we have taken a sample. This example is obtained by repeating the algorithm six times. According to the level of significance 0.001 and interval $\left(-\infty, t_{\alpha}\right)$, there is no reason to reject the null hypothesis and no significant difference between the target values of the genetic algorithm and GAMS software.

$$
\begin{aligned}
& \left\{\begin{array}{l}
H_{0}: Z_{G A}=Z_{G A M S} \\
H_{1}: Z_{G A}>Z_{G A M S}
\end{array}\right. \\
& t_{0}=\frac{\bar{z}_{G A}-Z_{G A M S}}{\frac{S}{\sqrt{6}}} \\
& \mathrm{~S}=\sqrt{\frac{\sum_{i=1}^{100}\left(\bar{z}_{G A}-Z_{G A}\right)^{2}}{5}} \\
& \left(-\infty, t_{\alpha}\right)=(-\infty, 5.2076)
\end{aligned}
$$




\section{Scenario 1:}

OF1:

$t_{0}=\frac{\bar{z}_{G A}-53974360}{\frac{S}{\sqrt{6}}}=\frac{54768333.45-53974360}{\sqrt{1.39 E+11 / 6}}=5.205$

OF2:

$t_{0}=\frac{\bar{z}_{G A}-763253.4}{\frac{S}{\sqrt{6}}}-\frac{763253.401-763253.4}{\frac{0.002230471}{\sqrt{6}}}=1.0432$

\section{Scenario 2:}

OF1:

$t_{0}=\frac{\bar{z}_{G A}-53974360}{\frac{S}{\sqrt{6}}}=\frac{54489628-53974360}{253262.3 / \sqrt{6}}=4.964$

OF2

$t_{0}=\frac{\bar{z}_{G A}-763253.4}{\frac{S}{\sqrt{6}}}-\frac{763253.4233-763253.4}{0.021077 / \sqrt{6}}=2.6934$

\section{Middle size:}

\section{Scenario 1:}

OF1:

$t_{0}=\frac{\bar{z}_{G A}-234430516}{\frac{s}{\sqrt{6}}}-\frac{240515416.2-234430516}{\sqrt{1.5 E+13 / 6}}=3.8446$

Data Availability Not applicable

Code Availability Not applicable

\section{Declarations}

Conflict of Interest The authors declare no competing interests.

\section{References}

Abazari SR et al (2020) Prepositioning and distributing relief items in humanitarian logistics with uncertain parameters. Socio Econ Plan Sci 74:100933
Aday S, Aday MS (2020) Impact of COVID-19 on the food supply chain. Food Qual Saf 4(4):167-180

Ahumada O, Villalobos JR (2009) Application of planning models in the agri-food supply chain: a review. Eur J Oper Res 196(1):1-20

Amin SH, Zhang G (2013) A multi-objective facility location model for closed-loop supply chain network under uncertain demand and return. Appl Math Model 37(6):4165-4176

De Vito A, Gómez J-P (2020) Estimating the COVID-19 cash crunch: global evidence and policy. J Account Public Policy 39(2): 106741

Dhull S, Narwal M (2018) Prioritizing the drivers of green supply chain management in Indian manufacturing industries using fuzzy TOPSIS method: government, industry, environment, and public perspectives. Process Integr Optim Sustain 2(1):47-60

Eustachio Colombo P et al (2019) Optimizing school food supply: integrating environmental, health, economic, and cultural dimensions of diet sustainability with linear programming. Int J Environ Res Public Health 16(17):3019

Fakhrzad MB, Goodarzian F (2019) A fuzzy multi-objective programming approach to develop a green closed-loop supply chain network design problem under uncertainty: modifications of imperialist competitive algorithm. RAIRO-Oper Res 53(3):963-990

Ferrari L et al (2019) Can nudging improve the environmental impact of food supply chain? A systematic review. Trends Food Sci Technol 91:184-192

Ganesh Kumar C et al (2017) Agri-food supply chain management: literature review. Intell Inf Manag 9:68-96

Ganguly B et al (2019) Influence of controllable lead time, premium price, and unequal shipments under environmental effects in a supply chain management. RAIRO-Oper Res 53(4):1427-1451

Grida M et al (2020) Evaluate the impact of COVID-19 prevention policies on supply chain aspects under uncertainty. Transp Res Interdiscip Perspect 8:100240

Hobbs JE (2020) Food supply chains during the COVID-19 pandemic. Can J Agric Econ/Revue canadienne d'agroeconomie 68(2): $171-176$

Junge AL, Straube F (2020) Sustainable supply chains-digital transformation technologies' impact on the social and environmental dimension. Proc Manuf 43:736-742

Krishnan R et al (2020) Redesigning a food supply chain for environmental sustainability-an analysis of resource use and recovery. $\mathbf{J}$ Clean Prod 242:118374

Liu G (2018) The impact of supply chain relationship on food quality. Proc Comp Sci 131:860-865

Mahajan K, Tomar S (2021) COVID-19 and supply chain disruption: evidence from food markets in India. Am J Agric Econ 103(1):35-52

Mavrotas G, Florios K (2013) An improved version of the augmented $\varepsilon$-constraint method (AUGMECON2) for finding the exact pareto set in multi-objective integer programming problems. Appl Math Comput 219(18):9652-9669

Moghadam SS, Aghsami A, Rabbani M (2021) A hybrid NSGA-II algorithm for the closed-loop supply chain network design in e-commerce. RAIRO: Oper Res 55:1643

Mohtashami Z, Aghsami A, Jolai F (2020) A green closed loop supply chain design using queuing system for reducing environmental impact and energy consumption. J Clean Prod 242:118452

Nematollahi M, Tajbakhsh A (2020) Past, present, and prospective themes of sustainable agricultural supply chains: a content analysis. J Clean Prod 271:122201

Ogier M et al (2013) Service network design in short and local fresh food supply chain. RAIRO-Oper Res-Recherche Opérationnelle 47(4):445-464 
Perdana T et al (2020) Scenarios for handling the impact of COVID-19 based on food supply network through regional food hubs under uncertainty. Heliyon 6(10): 05128

Rizou M et al (2020) Safety of foods, food supply chain and environment within the COVID-19 pandemic. Trends Food Sci Technol 102:293-299

Rohmer S et al (2019) Sustainable supply chain design in the food system with dietary considerations: a multi-objective analysis. Eur J Oper Res 273(3):1149-1164

Saetta S, Caldarelli V (2020) How to increase the sustainability of the agri-food supply chain through innovations in 4.0 perspective: a first case study analysis. Proc Manuf 42:333-336

Segura $M$ et al (2020) Improving food supply chain management by a sustainable approach to supplier evaluation. Mathematics 8(11): 1952
Singh S et al (2021) Impact of COVID-19 on logistics systems and disruptions in food supply chain. Int J Prod Res 59(7):1993-2008

Zabir AA, Mahmud A, Islam MA, Antor SC, Yasmin F, Dasgupta A (2021) COVID-19 and food supply in Bangladesh: a review. South Asian Journal of Social Studies and Economics 10(1):15-23

Publisher's Note Springer Nature remains neutral with regard to jurisdictional claims in published maps and institutional affiliations. 